\title{
Gating of the L-Type Ca Channel in Human Skeletal Myotubes: An Activation Defect Caused by the Hypokalemic Periodic Paralysis Mutation R528H
}

\author{
James A. Morrill, ${ }^{1}$ Robert H. Brown $\mathrm{Jr}^{3}{ }^{3}$ and Stephen C. Cannon ${ }^{1,2,3}$ \\ ${ }^{1}$ Program in Neuroscience, Division of Medical Sciences, and ${ }^{2}$ Department of Neurobiology, Harvard Medical School, and \\ 3Department of Neurology, Massachusetts General Hospital, Boston, Massachusetts 02214
}

The skeletal muscle L-type Ca channel serves a dual role as a calcium-conducting pore and as the voltage sensor coupling t-tubule depolarization to calcium release from the sarcoplasmic reticulum. Mutations in this channel cause hypokalemic periodic paralysis (HypoPP), a human autosomal dominant disorder characterized by episodic failure of muscle excitability that occurs in association with a decrease in serum potassium. The voltage-dependent gating of L-type Ca channels was characterized by recording whole-cell $\mathrm{Ca}$ currents in myotubes cultured from three normal individuals and from a patient carrying the HypoPP mutation $\mathrm{R} 528 \mathrm{H}$. We found two effects of the
$\mathrm{R} 528 \mathrm{H}$ mutation on the L-type Ca current in HypoPP myotubes: (1) a mild reduction in current density and (2) a significant slowing of the rate of activation. We also measured the voltage dependence of steady-state L-type Ca current inactivation and characterized, for the first time in a mammalian preparation, the kinetics of both entry into and recovery from inactivation over a wide range of voltages. The $\mathrm{R} 528 \mathrm{H}$ mutation had no effect on the kinetics or voltage dependence of inactivation.

Key words: dihydropyridine receptor; L-type calcium channel; human skeletal muscle; cultured cells; familial periodic paralysis; patch clamp
The skeletal muscle L-type calcium channel occupies an important position in muscle physiology, serving both as a slowly activating voltage-dependent calcium channel and as a voltagedependent activator of calcium release from the sarcoplasmic reticulum (Rios and Brum, 1987; Tanabe et al., 1988). The gating properties of the L-type Ca channel have been well studied in frog fibers (Cota et al., 1983; Sanchez and Stefani, 1983; Cota and Stefani, 1989; Feldmeyer et al., 1990; Francini et al., 1992, 1996), native and cultured rodent muscle cells (Beam and Knudson, 1988; Delbono, 1992; Delbono and Stefani, 1993; Dirksen and Beam, 1995), and artificial bilayers fused with t-tubule membrane vesicles (Ma et al., 1991, 1996; Mejia-Alvarez et al., 1991). However, the human isoform of the channel has only recently begun to be characterized (Garcia et al., 1992; Sipos et al., 1995, 1997; Jurkat-Rott et al., 1998). Studies to date have revealed important differences between the human isoform and its relatives in other species (Garcia et al., 1992; Sipos et al., 1997), underscoring the need for a comprehensive description of the gating properties of the human channel.

Hypokalemic periodic paralysis (HypoPP) is an autosomal dominant disorder of muscle in which patients experience episodes of weakness in association with a reduction in the serum potassium concentration. The episodes begin in adolescence and often wane by the fifth or sixth decade of life, although patients can experience a late-onset chronic proximal weakness accompa-

\footnotetext{
Received July 2, 1998; revised Sept. 21, 1998; accepted Oct. 2, 1998.

This work was supported by the National Institutes of Health Grant R01AR42703, by the Esther A. and Joseph Klingenstein Fund, Inc. (S.C.C.), and by a Quan Predoctoral fellowship (J.A.M.). We thank Adriana Pechanova for performing the RT-PCR work. We also thank Dr. Bruce Bean and Dr. Donnella Green for helpful discussions and Vasanth Vedantham for helpful comments on this manuscript.

Correspondence should be addressed to Dr. Stephen Cannon, EDR 413A, Massachusetts General Hospital, Boston, MA 02214.

Copyright (C) 1998 Society for Neuroscience $\quad 0270-6474 / 98 / 1810320-15 \$ 05.00 / 0$
}

nied by myopathic changes (Lehmann-Horn et al., 1994). In vitro studies of biopsied muscle fibers revealed that caffeine-induced contracture was normal in HypoPP fibers (Ruff, 1991) but that reducing $\left[\mathrm{K}^{+}\right]_{\mathrm{o}}$ caused an unexpected paralytic depolarization of the fibers, whereas normal fibers became hyperpolarized under these conditions (Rüdel et al., 1984). Although HypoPP is primarily a disorder of muscle membrane excitability, microelectrode studies failed to identify an abnormal conductance or pump (Rüdel et al., 1984).

Linkage studies placed the genetic locus of HypoPP at chromosome 1q31-32, in the vicinity of the gene encoding the $\alpha_{1}$ subunit of the skeletal muscle L-type calcium channel $\left(\alpha_{1 \mathrm{~S}}\right)$ (Fontaine et al., 1994). Further analysis demonstrated the existence of specific $\alpha_{1 \mathrm{~S}}$ mutations that cosegregated with the disease in families. Three mutations were found: R528H ( $\sim 50 \%$ of cases), a substitution of histidine for the outermost arginine residue in the S4 region of domain II of the channel (Jurkat-Rott et al., 1994); R1239H ( $~ 50 \%$ of cases), an arginine to histidine substitution at the outer end of domain IV S4; and R1239G (only one family), a substitution of glycine for arginine at the same position (Ptacek et al., 1994; Fouad et al., 1997).

The location of the missense mutations within putative voltage sensors of the L-type $\mathrm{Ca}$ channel predicted an alteration of the voltage dependence of channel gating. In an effort to define the effect of the HypoPP mutations, Sipos et al. (1995) recorded Ca currents in myotubes cultured from HypoPP patients heterozygous for the $\mathrm{R} 528 \mathrm{H}$ and $\mathrm{R} 1239 \mathrm{H}$ mutations. R1239H myotubes had a $62 \%$ reduction in L-type Ca current density but exhibited no gating defect. In contrast, $\mathrm{R} 528 \mathrm{H}$ myotubes had no reduction in L-type Ca current density but showed a remarkable $40 \mathrm{mV}$ hyperpolarizing shift in the voltage dependence of steady-state inactivation. Lerche et al. (1996) failed to confirm this finding in human embryonic kidney cells transiently expressing the cardiac isoform of the $\alpha_{1}$ subunit $\left(\alpha_{1 \mathrm{C}}\right)$ carrying the homolog of the 
R528H mutation (the $\beta, \alpha_{2} \delta$, and $\gamma$ subunits were coexpressed). The voltage dependence of both activation and inactivation was shifted $5 \mathrm{mV}$ in the hyperpolarizing direction, and the current density was reduced by $38 \%$. Lapie et al. (1996) recorded L-type Ca currents in mouse $\mathrm{L}$ cells expressing the rabbit $\alpha_{1 \mathrm{~s}}$ subunit carrying $\mathrm{R} 528 \mathrm{H}$ and found that the voltage dependence of activation, the voltage dependence and rate of inactivation, and sensitivity to the dihydropyridine agonist Bay K 8644 were the same as in cells transfected with the normal construct. Most recently, additional recordings from human myotubes carrying the $\mathrm{R} 528 \mathrm{H}$ mutation and recordings from dysgenic myotubes expressing $\mathrm{R} 528 \mathrm{H}$ in the rabbit $\alpha_{1 \mathrm{~S}}$ subunit both failed to reveal a large shift in the voltage dependence of inactivation. Instead, a small parallel shift of $6-8 \mathrm{mV}$ was found in the voltage dependence of both activation and inactivation (Jurkat-Rott et al., 1998). Thus, the gating defect initially found in human myotubes has not been reproduced, either in several heterologous expression systems or in the native human muscle cells in which it was originally described.

We recorded $\mathrm{Ca}$ currents in human myotubes cultured from three normal individuals and from a patient with the $\mathrm{R} 528 \mathrm{H}$ mutation to define further the voltage dependence of gating for both the wild-type and the R528H L-type Ca channel. We found that the density of L-type $\mathrm{Ca}$ current was mildly reduced in HypoPP cells compared with normals. The mutation slowed the kinetics of activation but did not affect the voltage dependence of activation, the kinetics of deactivation, or the voltage dependence or kinetics of inactivation. Our findings suggest that the R528H mutation modestly reduces current density and affects a transition state along the activation pathway but leaves the channel otherwise unaffected.

\section{MATERIALS AND METHODS}

Cell culture. Human muscle satellite cells (myoblasts) were obtained from muscle biopsies taken from a HypoPP patient carrying the R528H mutation. The biopsies were performed for clinical diagnostic purposes in accordance with a protocol approved by the Subcommittee on Human Studies at the Massachusetts General Hospital. Normal satellite cells were obtained from muscle tissue discarded from surgery on three patients with no neuromuscular disease. Muscle samples were dissociated at $37^{\circ} \mathrm{C}$ in PBS (Life Technologies, Gaithersburg, MD) containing 1 $\mathrm{mg} / \mathrm{ml}$ trypsin (Sigma, St. Louis, MO), $1.5 \mathrm{mg} / \mathrm{ml}$ collagenase (Sigma), and $1 \mathrm{mg} / \mathrm{ml}$ bovine serum albumin (Sigma). The digested muscle cells were centrifuged for $10 \mathrm{~min}$ at $1000 \mathrm{rpm}$, and the pellet was resuspended in high-glucose DMEM (Life Technologies) containing $4.5 \mathrm{gm} / \mathrm{dl}$ glucose, 25 mM HEPES (Mediatech, Washington, DC), $20 \%$ fetal bovine serum (FBS; Intergen, Purchase, NY), 2 mm L-glutamine (Sigma), 100 $\mathrm{U} / \mathrm{ml}$ penicillin (Sigma), and $100 \mu \mathrm{g} / \mathrm{ml}$ streptomycin (Sigma) and was plated in a $100 \mathrm{~mm}$ Petri dish for growth in a $5 \% \mathrm{CO}_{2}$ atmosphere at $37^{\circ} \mathrm{C}$. When the freshly dissociated cells were $75-80 \%$ confluent, they were treated lightly with a solution of trypsin and EDTA (Sigma) in PBS, spun down, resuspended in growth medium containing 5\% DMSO (Sigma), and frozen in aliquots at $-80^{\circ} \mathrm{C}$ for later use.

Aliquots of myoblasts were periodically thawed and propagated (in a $5 \% \mathrm{CO}_{2}, 37^{\circ} \mathrm{C}$ incubator) in a growth medium containing MCDB 120 medium (JRH Biologicals, Lenexa, KS), 20\% FBS, 2 mM L-glutamine, $100 \mathrm{U} / \mathrm{ml}$ penicillin, and $100 \mu \mathrm{g} / \mathrm{ml}$ streptomycin. After they had grown to confluency (3-4 d), myoblasts were induced to fuse and differentiate into myotubes by replacing the growth medium with a differentiation medium containing DMEM, 1.5\% FBS, 2 mM L-glutamine, $100 \mathrm{U} / \mathrm{ml}$ penicillin, $100 \mu \mathrm{g} / \mathrm{ml}$ streptomycin, and $25 \mathrm{~mm}$ HEPES. The differentiation process took 4-6 d, after which myotubes could be maintained in the differentiation medium and used for recording for 2-3 weeks.

We verified that both the R528H and wild-type alleles were transcriptionally active in the primary cultures of HypoPP myotubes. RNA was isolated from a $75 \mathrm{~cm}^{2}$ confluent culture of myotubes using the MicroFastTrack Kit (Invitrogen, San Diego, CA). Reverse transcription was primed with random hexamers, and a 140 base pair (bp) cDNA was amplified using PCR. Because the forward primer (5'-GGAGATCCTGCTGGTGGAGTCGGG) and reverse primer (5'-GGAAAGACTCAGGACTGATGTG) span an intron $(\sim 800 \mathrm{bp})$, the $140 \mathrm{bp}$ PCR product was amplified from complementary, and not genomic, DNA. The $\mathrm{R} 528 \mathrm{H}$ mutation causes the loss of a BbvI restriction site within the amplified segment. The PCR product amplified from normal myotubes was completely cut by BbvI. The product obtained from HypoPP cells was only partially cut, consistent with expression of both wild-type and mutant alleles.

Calcium current recordings. Myotubes were detached from the bottom of the culture dish with a brief (3-5 min) treatment with trypsin and EDTA solution and were triturated gently using a $1 \mathrm{ml}$ plastic pipette to create rounded myotube fragments. The myotube fragments were plated on $12 \mathrm{~mm}$ coverslips and allowed to settle for 30-60 min. Whole-cell patch-clamp recordings were obtained from the fragments using an Axopatch 200A patch-clamp amplifier (Axon Instruments, Foster City, $\mathrm{CA}$ ) under control of a custom stimulation/recording program written in AxoBASIC and running on an IBM-compatible 486-based computer. Patch-clamp electrodes were fabricated from borosilicate glass capillary tubes ( $1.65 \mathrm{~mm}$ outer diameter; VWR Scientific, West Chester, PA) using a multistage puller (Sutter Instruments, Novato, CA), tip-coated with Sylgard, and fire-polished to a final tip resistance (in bath solution) of 2-4 $\mathrm{M} \Omega$. Whole-cell capacitance compensation was not used in the recordings because the large size of the myotube fragments [the average membrane capacitance was $123.9 \pm 3.3 \mathrm{pF}(n=149)$ and $170.9 \pm 7.6 \mathrm{pF}$ $(n=101)$ for normal and HypoPP fragments, respectively] exceeded the maximal analog compensation for the CV201A head stage (100 pF). Series resistance was partially compensated by the analog circuitry of the amplifier. On average, the series resistance after compensation was $6.1 \pm$ 0.2 and $5.6 \pm 0.2 \mathrm{M} \Omega$ for normal and HypoPP fragments, respectively. For all of the cells used in this study, the voltage-clamp time constant was $<1.4 \mathrm{msec}$ (on average, $\tau_{\text {clamp }}$ was $0.70 \pm 0.02$ and $0.88 \pm 0.03 \mathrm{msec}$ for the normal and HypoPP fragments, respectively). The voltage error attributable to residual series resistance was always $<5 \mathrm{mV}$. The amplifier output was filtered at $1 \mathrm{kHz}$ and sampled at $2 \mathrm{kHz}$ using an LM900 interface (Dagan Corporation, Minneapolis, MN). All experiments were performed at room temperature $\left(22^{\circ} \mathrm{C}\right)$ except those studying the rate of deactivation; for those experiments, the recording chamber was maintained at $12-13^{\circ} \mathrm{C}$ using a Peltier device connected to a temperature controller (Medical Systems, Greenvale, NY).

Recording solutions. Solutions were designed to maximize calcium currents and to block sodium and potassium currents. T-type Ca currents were distinguished from L-type Ca currents using depolarizing conditioning pulses or, in a few cases, by subtraction of dihydropyridine (nitrendipine or nimodipine)-sensitive current. The bath solution contained (in mM): 120 TEA-Cl, $10 \mathrm{CaCl}_{2}, 1 \mathrm{MgCl}_{2}, 10 \mathrm{HEPES}, 5$ glucose, 0.002 TTX, and 0.1 EGTA, pH adjusted to 7.4 with TEA-OH. The pipette solution contained (in mM): $130 \mathrm{CsCl}, 0.5 \mathrm{MgCl}_{2}, 10 \mathrm{HEPES}$, and 1 EGTA, $\mathrm{pH}$ adjusted to 7.2 with $\mathrm{CsOH}$. Because rundown of the L-type Ca current did not occur even during long experiments, the internal solution was not supplemented with $5 \mathrm{~mm} \mathrm{Mg-ATP}$ and $5 \mathrm{~mm}$ phosphocreatine as in the experiments of Sipos et al. (1995) and JurkatRott et al. (1998). Nitrendipine was diluted from a $1 \mathrm{~mm}$ stock in DMSO to a final concentration of $0.5,5$, or $10 \mu \mathrm{M}$ in the bath solution. Nimodipine was diluted from a $3 \mathrm{~mm}$ DMSO stock to a final concentration of 5,10 , or $50 \mu \mathrm{M}$.

Data analysis. Leak subtraction was performed on-line by scaling and subtracting the average response $(n=5-15)$ to $30 \mathrm{mV}$ steps from the holding potential, which was usually $-100 \mathrm{mV}$. Because the cell capacitance was too large to be fully compensated by the amplifier circuitry, the capacitance transients at the onset and offset of depolarized command pulses often saturated the patch-clamp amplifier. For this reason, leaksubtracted currents usually had subtraction artifacts at the onset and offset of the voltage pulse, which were routinely blanked from traces presented in the figures. Curve fitting was performed off-line using AxoBASIC or SigmaPlot (Jandel Scientific, San Rafael, CA). L-type Ca current density was calculated as the maximum current amplitude divided by the cell capacitance. Error bars in the figures indicate the SEM, and results presented in the text are means \pm SEM. Student's $t$ test was used to determine the statistical significance of differences between two sets of averaged data, whereas differences among multiple data sets were analyzed using one-way ANOVA and the "protected $t$ test" [a version of Student's $t$ test weighted for multiple comparisons (Welkowitz et al., 1976)]. 
A.
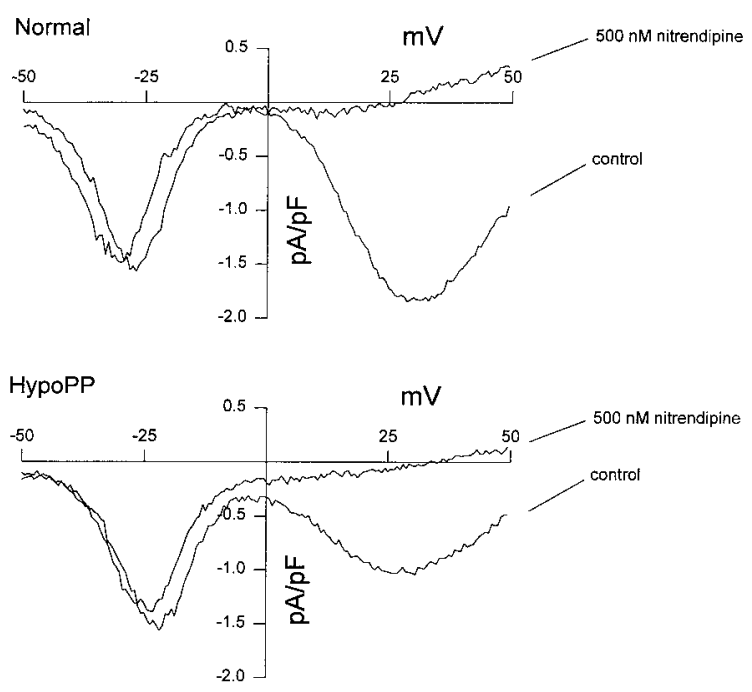

B.

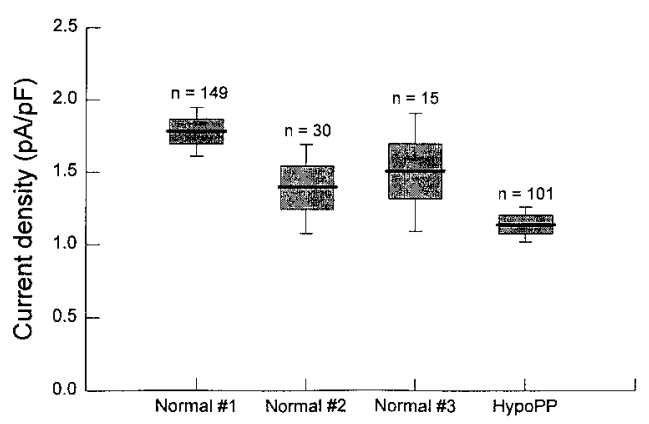

Figure 1. The density of L-type Ca current is mildly reduced in $\mathrm{R} 528 \mathrm{H}$ HypoPP myotubes. $A$, A slow voltage ramp $(0.12 \mathrm{mV} / \mathrm{msec})$ from -100 to $+50 \mathrm{mV}$ was applied to a normal cell and a HypoPP cell, eliciting a low-threshold $\mathrm{Ca}$ current carried by $\mathrm{T}$-type $\mathrm{Ca}$ channels and a highthreshold current carried by L-type Ca channels. The current response was normalized by cell capacitance and is presented as current density in picoamperes per picofarad. Nitrendipine, added to the bath to a final concentration of $500 \mathrm{nM}$, selectively blocked the L-type component in both cells. Although the T-type currents in these two cells were of comparable size, the density of L-type $\mathrm{Ca}$ current was approximately one-half as large in the HypoPP cell as in the normal cell. No third-type component of $\mathrm{Ca}$ current was seen. $B$, The mean L-type Ca current density was only mildly smaller in HypoPP cells than in normal cells. The peak current density in each cell was calculated as the maximum L-type Ca current measured during a $500 \mathrm{msec}$ voltage pulse to +20 or $+30 \mathrm{mV}$ divided by the cell capacitance. The box plot shows the mean (thick horizontal lines) current density values measured in $101 \mathrm{R} 528 \mathrm{H}$ cells and control cells obtained from three normal subjects, along with the SEM (represented by the limits of the boxes) and the 95\% confidence interval (represented by the error bars). The means were not equal (one-way ANOVA, $\left.F=10.7 ; p<10^{-5}\right)$. The differences in means for all four sets of cells $(1.14 \pm 0.06 \mathrm{pA} / \mathrm{pF}$ for the HypoPP cells vs $1.78 \pm 0.09,1.39 \pm$ 0.15 , and $1.50 \pm 0.19 \mathrm{pA} / \mathrm{pF}$ for the three sets of normal cells) were compared in all six possible pairwise combinations. Current density was reduced in HypoPP cells compared with normal \#1 $(p<0.001)$ but was not statistically different from the other two groups of normals (each of which had smaller sample sizes than normal \#1).

\section{RESULTS}

\section{L-type Ca current density in normal and R528H HypoPP myotubes}

Figure $1 A$ shows the response of a normal myotube and a HypoPP myotube to a slow ramp protocol, in which the voltage was increased from -100 to $+50 \mathrm{mV}$ over a period of $1.25 \mathrm{sec}$ (giving a rate of change of $0.12 \mathrm{mV} / \mathrm{msec})$. In agreement with previous studies on cultured mammalian muscle cells (Beam and Knudson, 1988; Dirksen and Beam, 1995), the ramp protocol demonstrated two major components of $\mathrm{Ca}$ current. T-type current activated at -50 to $-40 \mathrm{mV}$ and showed prominent inactivation during the ramp, giving rise to a sharp peak at -20 to $-30 \mathrm{mV}$. L-type $\mathrm{Ca}$ current activated slowly at much more depolarized potentials ( 0 to $+20 \mathrm{mV}$ ) and showed little inactivation during the ramp (the reduction in inward current toward the end of the ramp occurred both because of the reduction in the driving force on calcium ions and because of a small amount of background outward current). As expected, the L-type component, but not the T-type component, was selectively blocked by the dihydropyridine drug nitrendipine (500 nM). The T-type current density was similar in normal and HypoPP cells (as in Fig. 1 $A$ ). The density of L-type $\mathrm{Ca}$ current (measured as the maximum L-type Ca current during a $500 \mathrm{msec}$ voltage pulse from -100 to +20 or $+30 \mathrm{mV}$ divided by the cell capacitance) was modestly reduced in HypoPP cells compared with all three sets of normal cells tested (Fig. 1B). The mean current density values in the three sets of normal myotubes were $1.78 \pm 0.09 \mathrm{pA} / \mathrm{pF}$ (normal \#1; $n=149$ ), $1.39 \pm 0.15 \mathrm{pA} / \mathrm{pF}$ (normal \# $2 ; n=30$ ), and $1.50 \pm 0.19 \mathrm{pA} / \mathrm{pF}$ (normal \#3; $n=15$ ), whereas the current density in HypoPP myotubes was $1.14 \pm 0.06$ $\mathrm{pA} / \mathrm{pF}(n=101)$. One-way ANOVA performed on the four data sets demonstrated that there was a significant difference among the means $\left(F=10.7 ; p<10^{-5}\right)$. When the differences in means of the four data sets were compared in all possible pairwise combinations using the protected $t$ test (Welkowitz et al., 1976), the only statistically significant difference found was between normal \#1 and the set of HypoPP cells $(p<0.001)$. The three normals were not significantly different from each other, and normal \#2 and normal \#3 were not significantly different from the HypoPP set. The current density in all sets of myotubes was quite variable, perhaps because of day-to-day and batch-to-batch changes in the degree of myotube differentiation.

In contrast to other studies of human myotubes (Rivet et al., 1992; Sipos et al., 1995, 1997; Jurkat-Rott et al., 1998), we could not detect a distinct "third-type" of transient calcium current in our myotubes. In both normal and HypoPP cells studied using voltage steps $(n=11)$, the current-voltage relationship of the transient current appeared to have a single maximum between -30 and $-20 \mathrm{mV}$, with no additional increase above $-10 \mathrm{mV}$ (data not shown). Moreover, only one distinct peak, having the low threshold of the T-type current, was observed in slow ramp traces recorded in the presence of saturating nitrendipine or nimodipine ( $n=5$ normal and 5 HypoPP cells; see Fig. 1 for examples).

\section{The range and steepness of activation are the same in normal and R528H HypoPP myotubes}

Despite the location of the $\mathrm{R} 528 \mathrm{H}$ mutation in the $\mathrm{S} 4$ region of domain II of the skeletal muscle L-type calcium channel, to date no study of this mutation has revealed a substantial effect on the steepness or position of the $G(V)$ curve. We examined the voltage dependence of activation by measuring the peak L-type $\mathrm{Ca}$ current during a series of $1 \mathrm{sec}$ test pulses (Fig. 2). A $2 \mathrm{sec}$ conditioning pulse to $-30 \mathrm{mV}$ was applied before each test pulse to inactivate the T-current, facilitating the detection of the peak L-type Ca current. Typically, as shown in the examples in Figure $2 A$, the L-type $\mathrm{Ca}$ current was detectable at $0 \mathrm{mV}$, reached a maximum value at $+20 \mathrm{mV}$, and then decreased with further depolarization because of the reduction in the driving force for 
A

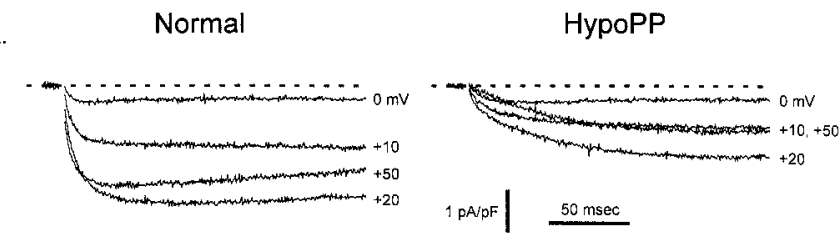

B.

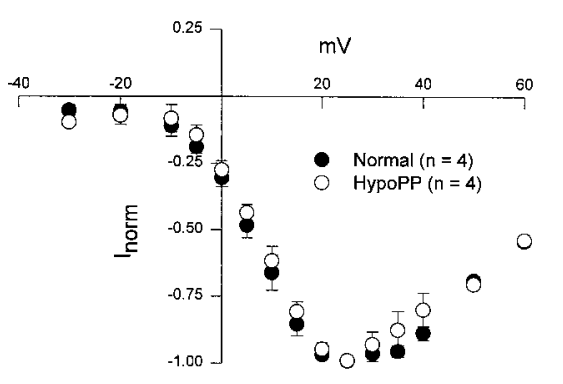

C.

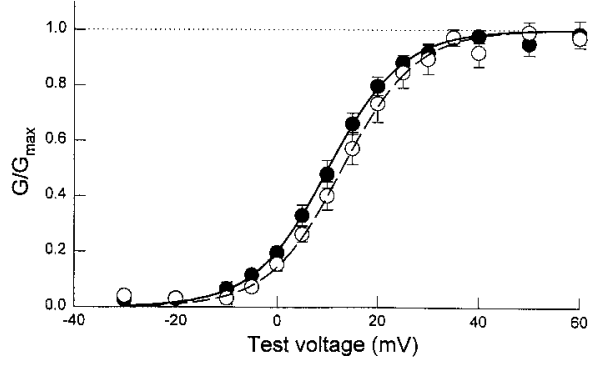

Figure 2. L-type Ca currents in normal and R528H HypoPP myotubes activate over the same voltage range. $A$, L-type $\mathrm{Ca}$ current was elicited by $1 \mathrm{sec}$ depolarizations to a range of test potentials after a $2 \mathrm{sec}$ conditioning pulse to $-30 \mathrm{mV}$ to inactivate the T-current. The holding potential was $-100 \mathrm{mV}$. Currents are leak subtracted, and $4 \mathrm{msec}$ of each trace representing the initial capacitive transient is blanked. $B$, The voltage dependence of the peak L-type $\mathrm{Ca}$ current is the same in normal and HypoPP cells. The peak L-type $\mathrm{Ca}$ current at each voltage was estimated from traces generated as described in $A$, normalized by the maximum current measured, and plotted as a function of test potential. The normal data are from cells derived from a single control biopsy (cells from the two other control biopsies gave similar results). $C, G(V)$ curves, computed from the data in $B$ as $I_{\text {peak }} /\left(V-E_{\text {rev }}\right)$, are similar for normal and HypoPP cells. The solid and dashed lines are Boltzmann fits to the data from normal and HypoPP cells, respectively, of the form: $G / G_{\max }=1 /(1+\exp [-(V-$ $\left.\left.V_{1 / 2}\right) / k\right]$ ). Normal data: $V_{1 / 2}=10.2 \pm 1.3 \mathrm{mV}$, and $k=7.4 \pm 0.7 \mathrm{mV}$. HypoPP data: $V_{1 / 2}=13.0 \pm 1.9 \mathrm{mV}$, and $k=7.3 \pm 0.7 \mathrm{mV}$.

calcium. The peak L-type Ca current was measured as a function of test potential and normalized to the maximum value (observed at +20 or $+30 \mathrm{mV})$.

Families of L-type Ca currents were recorded in cells from one HypoPP patient and three normal controls. In Figure $2 B$ the average of the amplitude-normalized peak L-type $\mathrm{Ca}$ current measured in HypoPP cells and in one set of control cells is plotted as a function of test potential. Normal and HypoPP cells showed a similar threshold for activation of the L-type Ca current $(-5$ to $-10 \mathrm{mV})$ and a similar position of the peak current $(+20$ to $+30 \mathrm{mV})$. In Figure $2 C$ these data have been transformed to a conductance-voltage $[G(V)]$ curve using the equation: $G(V)=$ $I(V) /\left(V-E_{\text {rev }}\right)$, where $E_{\text {rev }}$, the reversal potential for the L-type $\mathrm{Ca}$ current, was estimated by linear extrapolation of the $I-V$ curve. The $G(V)$ curves measured for normal and HypoPP cells overlap throughout the range of activation, from the threshold near $-5 \mathrm{mV}$ to the point at which conductance is maximal, around +40 to $+50 \mathrm{mV}$. The solid and dashed lines are fits to the normal and HypoPP data, respectively, of the Boltzmann function: $G(V) / G_{\max }=1 /\left(1+\exp \left[-\left(V-V_{1 / 2}\right) / k\right]\right)$, where $V_{1 / 2}$ is the voltage at which the conductance is half maximal and $k$ describes the steepness of activation. For the normal cells, $V_{1 / 2}=10.2 \pm 1.3$ $\mathrm{mV}$, and $k=7.4 \pm 0.7 \mathrm{mV}$; whereas for the HypoPP cells, $V_{1 / 2}=$ $13.0 \pm 1.9 \mathrm{mV}$, and $k=7.3 \pm 0.7 \mathrm{mV}$ (not significantly different). $G(V)$ curves recorded in the two additional sets of normal cells were nearly identical (data not shown).

\section{The rate of activation is slower in $\mathrm{R} 528 \mathrm{H}$ HypoPP myotubes than in normal myotubes}

To characterize further the voltage dependence of activation, we measured the rate of activation of L-type Ca current. A $2 \mathrm{sec}$ conditioning pulse to $-30 \mathrm{mV}$ to inactivate the T-type current was followed by a $500 \mathrm{msec}$ or $1 \mathrm{sec}$ pulse to a series of test potentials. Traces were digitally smoothed with a $100 \mathrm{~Hz}$ Gaussian filter, normalized to peak amplitude, and then averaged over all cells to construct a mean activation time course for test potentials ranging from +10 to $+50 \mathrm{mV}$. The mean time courses obtained in cells from the three control patients and the HypoPP patient are compared in Figure 3. At all test potentials except +10 $\mathrm{mV}$, the mean activation time course of the HypoPP current was markedly slower than the mean time course recorded in the three sets of normal cells.

Activation time courses were fit to the equation: $I(t)=m(t) *$ $h(t)$, where $m$ and $h$ are single exponentials describing the activation and inactivation, respectively, of the channel, as has been done by a number of others (Mejia-Alvarez et al., 1991; Tanabe et al., 1991; Delbono, 1992; Garcia et al., 1992; Dirksen and Beam, 1995; Ma et al., 1996; Sipos et al., 1997; Jurkat-Rott et al., 1998). Figure $4 A$ shows activation time courses recorded from one normal and one HypoPP cell using the protocol shown in the inset. To avoid interference by a residual capacitive transient (blanked in Fig. 4A), we began the fits 8 msec after the start of the test pulse. The dashed lines shown with the traces are fits derived from the $m * h$ model, and the estimated value of $\tau_{m}$, the time constant of activation, is given with each trace. For most of the Ca currents we recorded, this model fit the activation time course well, implying that the activation process, most likely involving several transitions, was dominated by one rate-limiting eigenvalue. [The mean time courses that were calculated from the raw traces (Fig. 3) are more complicated because of the contribution of multiple single-exponential components.]

Figure $4 B$, left, shows the voltage dependence of the activation time constants measured in the three sets of normal cells and in the HyopPP cells. As has been reported in other mammalian preparations, including neonatal mouse myotubes (Dirksen and Beam, 1995) and human myotubes (Sipos et al., 1997; Jurkat-Rott et al., 1998), the activation time constant in the normal cells was smallest at $+10 \mathrm{mV}$ and was only weakly voltage dependent between +20 and $+50 \mathrm{mV}$, with a slight trend toward slower activation with increasing voltage. The activation time constant in HypoPP cells was slower at all test voltages and became progressively more sluggish compared with the control value at more depolarized test voltages. At test potentials of +40 and $+50 \mathrm{mV}$, the channels from mutant myotubes activated almost three times as slowly as did the channels at $+10 \mathrm{mV}$.

Activation kinetics were also quantified by a modelindependent parameter, the time to half peak $\left(t_{1 / 2}\right)$ of the activation time course. This parameter was measured from the same activation time courses that were used in the single-exponential 

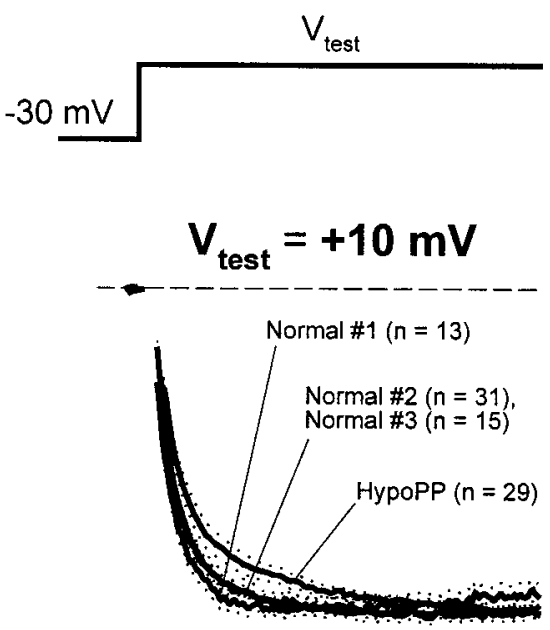

Figure 3. The L-type Ca current activates more slowly in HypoPP cells than in normal cells. The traces are averages of smoothed, normalized currents recorded at each test potential in cells from three different controls and one HypoPP patient. The first 8-10 msec of each average current response has been blanked to remove the averaged capacitive transient (which was made wider by the $100 \mathrm{~Hz}$ smoothing algorithm). Currents were elicited by depolarization to the indicated test potentials after a $2 \mathrm{sec}$ conditioning pulse to -30 to inactivate the T-current. The holding potential was $-100 \mathrm{mV}$. The solid lines trace the mean current as a function of time, whereas the dotted lines show the SEM. The dashed horizontal lines represent the zero current level. On average, the HypoPP currents activated more slowly than did currents in controls for test potentials greater than $+10 \mathrm{mV}$.

\section{$+30 \mathrm{mV}$}
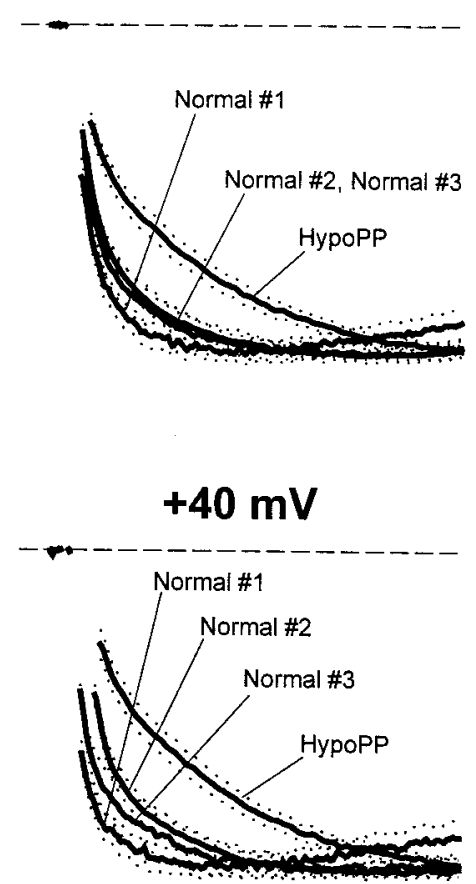

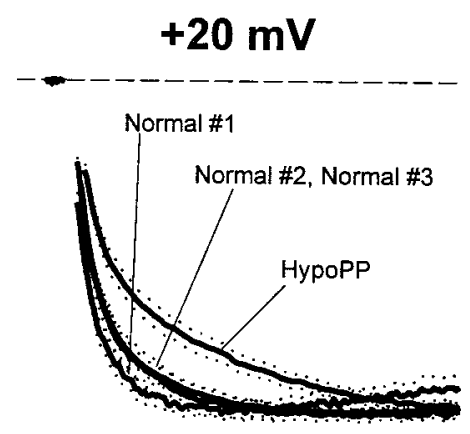

$40 \mathrm{msec}$

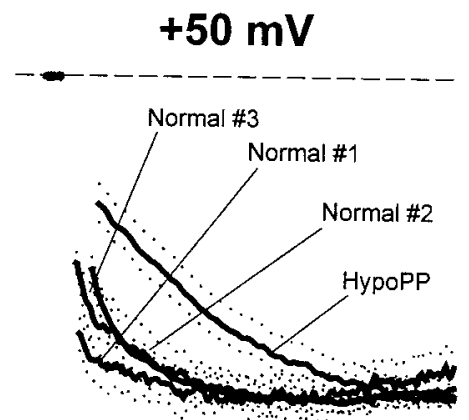

fits, and the results are shown in Figure $4 B$, right. The behavior of $t_{1 / 2}$ was qualitatively similar to the behavior of the activation time constant seen in Figure $4 B$; in normal cells the time to half peak was only weakly dependent on voltage, whereas in HypoPP cells the time to half peak increased sharply with depolarization, showing a nearly fourfold difference in magnitude between +10 and $+50 \mathrm{mV}$. Thus, a comparison of three different measures of activation kinetics (mean time courses, single-exponential fits, and measurements of $t_{1 / 2}$ ) suggested that the R528H mutation slowed the activation rate of the channel.

A recent study of the activation kinetics of the L-type $\mathrm{Ca}$ current in mouse muscular dysgenesis $(m d g)$ myotubes expressing the cloned rabbit $\alpha_{1 \mathrm{~S}}$ subunit concluded that slow activation was correlated with low channel expression (Adams et al., 1996). This finding raises the possibility that the slower activation we observed in HypoPP myotubes was a consequence of the observed reduction in current density rather than a direct effect of the R528H mutation. In agreement with Adams et al. (1996), we found that lower current density was correlated with slower activation in both normal and HypoPP myotubes. In fact, $\tau_{m}$ appeared to be even more steeply dependent on current density in our cells than in the previous study; the slope was -5 to -12.2 $\mathrm{msec}$ per $\mathrm{pA} / \mathrm{pF}$ in our cells, compared with -3.3 to $-5.5 \mathrm{msec}$ per $\mathrm{pA} / \mathrm{pF}$ in mouse myotubes. Nevertheless, we found that the relationship between $\tau_{m}$ and current density was different for the normal and HypoPP myotubes at all test potentials. When $\tau_{m}$ (measured at $+40 \mathrm{mV}$ ) is plotted against current density, the data from the HypoPP cells clearly fall along a different line than the data from the normal cells (Fig. $5 A$ ). Figure $5 B$ shows the dependence of $\tau_{m}$ on test potential for only those cells having a current density between 0.5 and $1.0 \mathrm{pA} / \mathrm{pF}$. The difference in $\tau_{m}$ between normal and HypoPP cells having similar current densities is just as striking as when all cells are pooled (as in Fig. $4 B$, left). The slow activation seen in the HypoPP cells is therefore not solely caused by low expression and is likely to be an independent effect of the mutation, because it clearly exceeds what would be predicted from the normal variation of $\tau_{m}$ with current density.

\section{The rate of deactivation is the same in normal and R528H HypoPP myotubes}

Because the $\mathrm{R} 528 \mathrm{H}$ mutation slowed the rate of activation, we also measured the rate of deactivation, which provides a measure 
A.

Normal
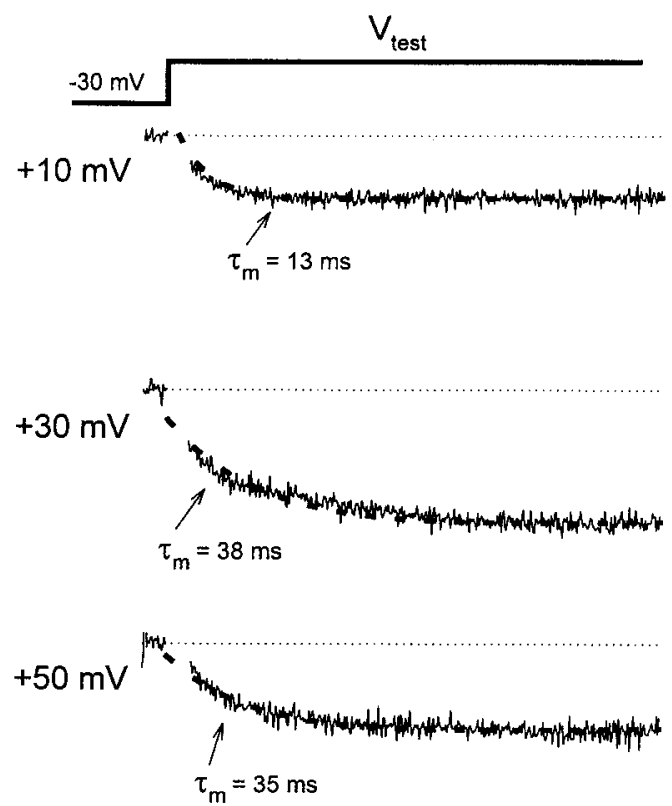

HypoPP
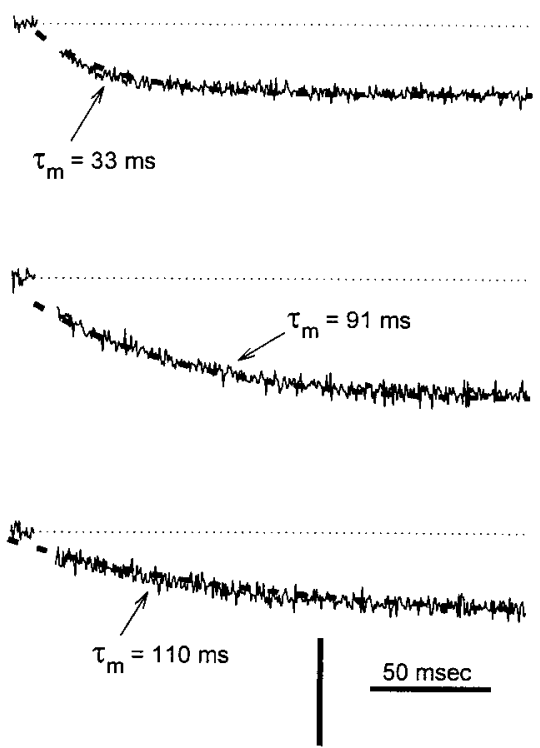

B.
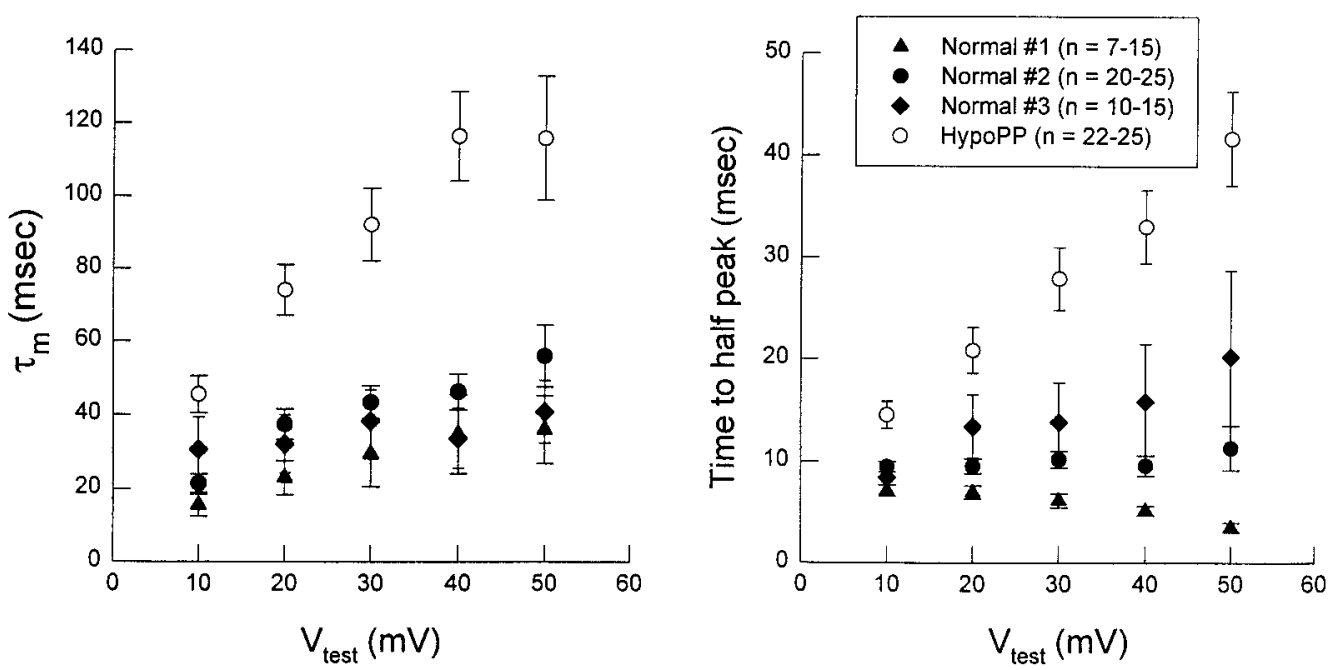

Figure 4. The sluggish activation of HypoPP currents becomes more pronounced with depolarization. $A$, Ca currents were elicited, as in Figures 2 and 3 , by $500 \mathrm{msec}$ or $1 \mathrm{sec}$ depolarizations to various test potentials after a $2 \mathrm{sec}$ conditioning pulse to $-30 \mathrm{mV}$ to inactivate the T-type current. The holding potential was $-100 \mathrm{mV}$. Currents, presented here in picoamperes per picofarad, were fit with a function describing a single-exponential activation process and an independent single-exponential inactivation process (dashed lines). In this model, $I(t)=I_{\max } * m * h$, where $m=(1-\exp [-(t-$ $\left.\left.\left.t_{\text {offset }}\right) / \tau_{m}\right]\right)$ describes the activation process and $h=\exp \left[-\left(t-t_{\text {offset }}\right) / \tau_{h}\right]$ describes the inactivation process (assuming that activation begins from zero current and inactivation proceeds toward zero current at all of the test potentials used). Traces were fitted from 8 msec onward to allow for the settling time of the voltage clamp, and the parameter $t_{\text {offset }}$ was allowed to take on positive or negative values. The first 8 msec of each test current is blanked in the figure. Vertical calibration: $1 \mathrm{pA} / \mathrm{pF}$ for the normal traces (all from the same normal cell); $0.5 \mathrm{pA} / \mathrm{pF}$ for the HypoPP traces (all from the same HypoPP cell). B, Left, The time constant of activation $\tau_{m}$ was measured as described in $A$ and plotted as a function of test potential. Data from the HypoPP cells and from three sets of control cells are compared. Although $\tau_{m}$ was only weakly voltage dependent in normal cells, $\tau_{m}$ became much larger at depolarized potentials in HypoPP cells. Right, The time to reach half-peak current was measured for the same activation time courses and was plotted as a function of test potential. The time to half peak showed little dependence on the test potential in normal cells but became much longer at depolarized potentials in HypoPP cells.

of the energy barrier traversed by the channel during closing (between the open state and the nearest closed state). Because the settling time of the whole-cell clamp was not fast enough to record deactivation at room temperature $\left(22^{\circ} \mathrm{C}\right)$, we used a Peltier device to cool the recording chamber to between 12 and $13^{\circ} \mathrm{C}$, thus slowing the rate of deactivation and allowing tail currents to be distinguished clearly from the "off" capacitive transient.

Figure $6 A$ shows tail currents recorded after repolarization to 
A.

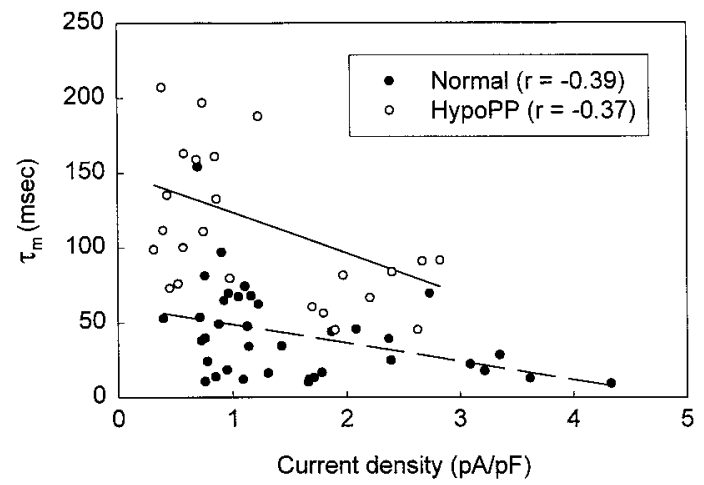

B.

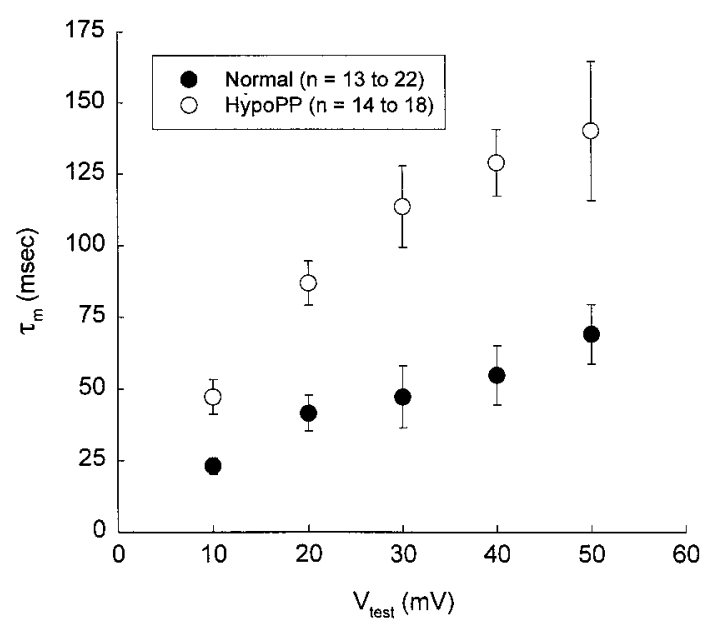

Figure 5. The slower activation seen in HypoPP myotubes is not attributable solely to lower average current density. $A$, The time constant of activation $\left(\tau_{m}\right)$ is plotted as a function of current density $\left(i_{\mathrm{Ca}}\right)$ for normal and HypoPP myotubes at $+40 \mathrm{mV}$. For both groups of cells, slower activation is correlated with lower current density, although the relationship between $\tau_{m}$ and $i_{\mathrm{Ca}}$ is different in the two groups. The solid and dashed lines show the negative linear correlation between $\tau_{m}$ and $i_{\mathrm{Ca}}$ in HypoPP and normal myotubes, respectively. Normal (dashed line): $\tau_{m}=$ $61-12.2 i_{\mathrm{Ca}}(r=-0.39 ; n=37)$. HypoPP (solid line): $\tau_{m}=151-27 i_{\mathrm{Ca}}$ $(r=-0.37 ; n=25) . B, \tau_{m}$ is plotted as a function of test voltage for only those currents with $i_{\mathrm{Ca}}>0.5 \mathrm{pA} / \mathrm{pF}$ and $<1.0 \mathrm{pA} / \mathrm{pF}$. Even in this restricted range of current densities, activation was markedly slower for HypoPP cells than for normal cells at every voltage, and the difference became more pronounced with depolarization.

various voltages after a $250 \mathrm{msec}$ step to $+50 \mathrm{mV}$. The sequence was preceded by a conditioning step to $-30 \mathrm{mV}$ to avoid T-type current contamination. Tail currents were fit with single exponentials (dashed lines superimposed on the traces). At $-10 \mathrm{mV}$, the fit required a nonzero asymptote, suggesting that there were some reopenings occurring during the tail current. At -30 and $-50 \mathrm{mV}$, reopenings are not expected [see the $G(V)$ curve, Fig. $2 C]$, and the single-exponential relaxation reflects deactivation. Figure $6 B$ shows the voltage dependence of $\tau_{\text {tail }}$, measured at tail potentials between -50 and $-10 \mathrm{mV}$ in HypoPP cells and in one set of control cells. There were no significant differences in the rates of deactivation in the normal and HypoPP cells at all tail potentials tested. In both types of cells, the deactivation rate was only mildly voltage dependent, changing $e$-fold per $86 \mathrm{mV}$ between -50 and $-20 \mathrm{mV}$.

\section{The voltage dependence of steady-state inactivation is the same in normal and R528H HypoPP myotubes}

Sipos et al. (1995) reported that the voltage dependence of inactivation induced by a $15 \mathrm{sec}$ conditioning pulse was shifted 40 $\mathrm{mV}$ in the hyperpolarized direction for L-type Ca currents in R528H HypoPP myotubes compared with normals, although this finding was not successfully reproduced in recordings made by the same investigators in myotubes from additional HypoPP patients (Jurkat-Rott et al., 1998). We measured the steady-state voltage dependence of inactivation using $60 \mathrm{sec}$ conditioning pulses that preceded test pulses to $+30 \mathrm{mV}$ (Fig. $7 A$ ). The peak L-type $\mathrm{Ca}$ current measured during the test pulse is plotted as a function of conditioning voltage in Figure $7 B$ for the HypoPP cells and for one set of normal cells. In contrast to the findings of Sipos et al. (1995) but in agreement with those of Jurkat-Rott et al. (1998), the voltage dependence of inactivation was not markedly shifted in HypoPP myotubes. The solid and dashed lines are Boltzmann fits to the data from normal and HypoPP cells, respectively, with $V_{1 / 2}=-16.9 \pm 2.3 \mathrm{mV}$ and $k=8.7 \pm 1.4 \mathrm{mV}$ for the normal cells and $V_{1 / 2}=-14.0 \pm 1.3 \mathrm{mV}$ and $k=8.8 \pm 0.94$ $\mathrm{mV}$ for the HypoPP cells (not significantly different). Steady-state inactivation curves measured in another set of normal cells (data not shown) gave $V_{1 / 2}=-18.0 \pm 3.4 \mathrm{mV}$ and $k=8.5 \pm 2.1 \mathrm{mV}$ $(n=4)$.

\section{Kinetics of inactivation of the skeletal muscle L-type Ca current}

Although R528H did not affect the voltage dependence of steadystate inactivation, it was still possible that the mutation affected the kinetics of inactivation. Moreover, although the rate of inactivation from the open state of the skeletal muscle L-type $\mathrm{Ca}$ current at depolarized voltages has been well studied in frog fibers (Cota et al., 1983; Sanchez and Stefani, 1983; Cota and Stefani, 1989; Francini et al., 1992) and mammalian preparations (Ma et al., 1991; Mejia-Alvarez et al., 1991; Delbono and Stefani, 1993; Caffrey, 1994; Jurkat-Rott et al., 1998), the rates of entry into and recovery from inactivation at more hyperpolarized voltages have not been studied comprehensively in any single species. For these reasons, we measured the rate of inactivation and recovery from inactivation of the L-type Ca current in HypoPP myotubes and myotubes from normal \#1.

The rate of inactivation of L-type Ca channels from the open state was measured by applying $20 \mathrm{sec}$ pulses to a range of strongly depolarized test potentials from a holding potential of $-100 \mathrm{mV}$. Figure $8 A$ shows the current measured in normal and HypoPP cells at $+10,+30$, and $+50 \mathrm{mV}$. The solid lines are single exponential fits to the slowly decaying phase of the currents, whose time constants ( $\tau_{h}$ values) are plotted as a function of voltage in Figure $8 B . \tau_{h}$ was similar in normal and HypoPP myotubes, and on average, the rate of inactivation was approximately twice as fast at $+50 \mathrm{mV}\left(\tau_{h}=\sim 1 \mathrm{sec}\right)$ as it was at $+10 \mathrm{mV}$ $\left(\tau_{h}=\sim 2 \mathrm{sec}\right)$.

The rate of entry into the inactivated state at more hyperpolarized voltages was measured using the three-pulse protocol shown in the inset of Figure $9 A$. In each trial, the control response was measured during a $200 \mathrm{msec}$ pulse to $+30 \mathrm{mV}$. After a $5 \mathrm{sec}$ gap at $-100 \mathrm{mV}$, a variable-length conditioning pulse was issued, followed by a $100 \mathrm{msec}$ gap at $-100 \mathrm{mV}$ and a $200 \mathrm{msec}$ test pulse to $+30 \mathrm{mV}$ to measure the degree of inactivation. The traces in Figure $9 A$ show test currents recorded in one normal cell and one HypoPP cell after $1-90 \mathrm{sec}$ conditioning pulses to $-10 \mathrm{mV}$. To determine the rate of entry into the inactivated state, we plotted 
A.

$$
\begin{gathered}
\text { Normal } \\
\left(T=12.6+/-0.1^{\circ} \mathrm{C}\right)
\end{gathered}
$$
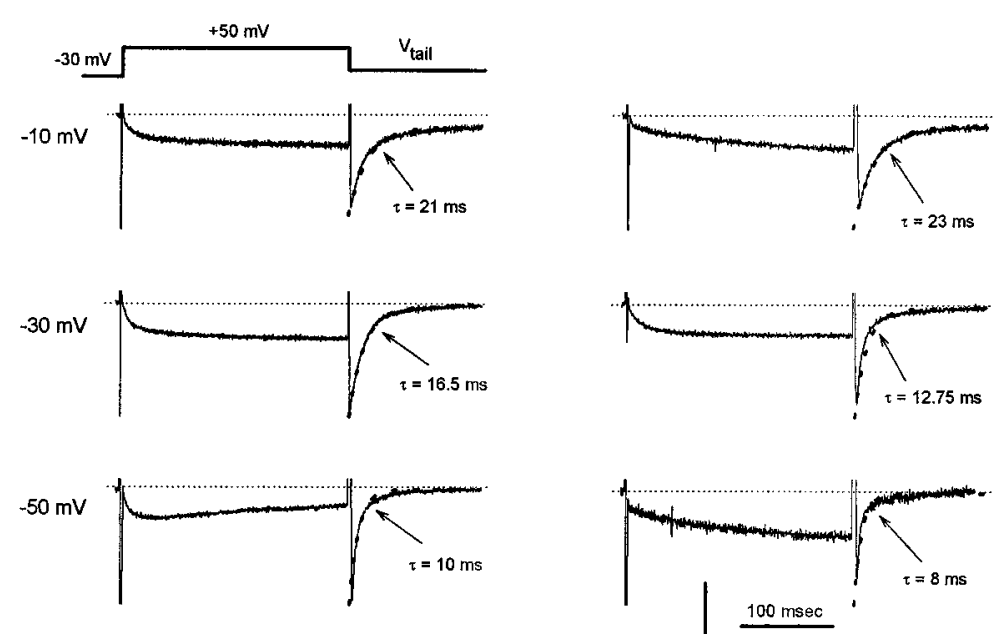

B.

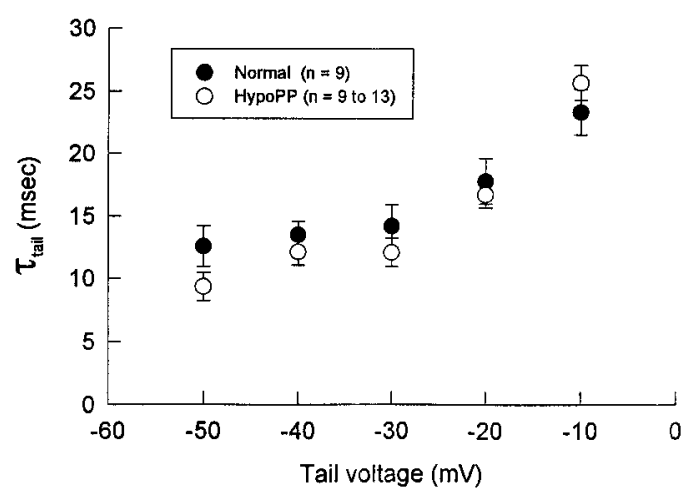

the test current, relative to the control current, as a function of $T_{\text {cond }}$. Figure $9 B$ shows that the kinetics of entry at $-30,-10$, and $+10 \mathrm{mV}$ was the same in normal and HypoPP myotubes. The time constant of entry $\tau_{\text {entry }}$ was determined by fitting a single exponential with a nonzero asymptote to each set of data; the dotted lines are fits to the mean data recorded in normal cells. The entry rate was strongly voltage dependent, occurring quickly and most completely at $+10 \mathrm{mV}$, more slowly at intermediate voltages, and quickly but incompletely at more hyperpolarized voltages. This pattern was confirmed by measurements of the rate of entry at -20 and $-40 \mathrm{mV}$ (data not shown).

To measure the rate of recovery from inactivation, we used a similar three-pulse sequence, shown in the inset to Figure $10 A$. A control current was elicited by a $200 \mathrm{msec}$ pulse to $+30 \mathrm{mV}$ to assay the amount of current in the absence of inactivation. After a $5 \mathrm{sec}$ gap, a $20 \mathrm{sec}$ conditioning pulse to $+30 \mathrm{mV}$ was applied to inactivate all of the channels, followed by a recovery step of variable length to allow recovery from inactivation and a test pulse to $+30 \mathrm{mV}$ to measure how much current had recovered. The traces in Figure $10 \mathrm{~A}$ show the test currents recorded in one normal cell and one HypoPP cell after recovery intervals ranging from 1 to $15 \mathrm{sec}$ at $-50 \mathrm{mV}$. The time course of recovery was measured by plotting the test current, relative to the control current, against $T_{\text {recovery }}$ The rate of recovery, quantified by fitting a single exponential to the time course (dotted lines), was similar in normal and HypoPP cells at all voltages tested (Fig.
Figure 6. The deactivation rate of L-type Ca current at $12-13^{\circ} \mathrm{C}$ is similar in normal and HyopPP cells. $A$, L-type tail currents were elicited by a protocol that included a conditioning step to $-30 \mathrm{mV}$ to remove T-type current and a $250 \mathrm{msec}$ command step to $+50 \mathrm{mV}$, followed by a step to various tail potentials. The holding potential was $-100 \mathrm{mV}$. Each trace is from a different cell. Vertical calibration: $80 \mathrm{pA}$ for all traces except the bottom right trace, for which the scale is $40 \mathrm{pA}$. The dashed lines show single-exponential fits to the tail current time course of the form: $\left(I_{\text {tail }}-I_{\mathrm{o}}\right) *\left[\exp \left(-t / \tau_{\text {tail }}\right)\right]+I_{\mathrm{o}}$, where $I_{\mathrm{o}}$, the asymptotic level for long times, was zero except when the tail potential was $-10 \mathrm{mV}$. To allow for settling of the clamp, we began the fits $8 \mathrm{msec}$ after the end of the test pulse and extrapolated back to the end of the command pulse. Capacitance transients were blanked at the start, but not at the end, of the test pulse. $B$, The rate of L-type Ca current deactivation is only weakly dependent on tail potential in both normal ( $n=9$; from a single control patient) and HyopPP $(n=9-13)$ myotubes.
$10 B)$. In all of the fits, the recovery curve relaxed to an asymptote that was lower than would be expected based on the steady-state inactivation curve (Fig. 7), suggesting that the fitted singleexponential phase was just the first phase of a slower recovery process.

Figure 11 shows $\tau_{\text {recovery }}, \tau_{\text {entry }}$, and $\tau_{h}$ plotted together on a semilogarithmic scale. As shown also in Figures 8-10, the kinetics of inactivation is similar in normal and HypoPP myotubes. The solid line is a fit to the normal data of a two-state model of inactivation, in which the rates governing transitions of the L-type Ca channel to and from the inactivated state vary exponentially with voltage. The model predicts single-exponential relaxations having a $\tau$ equal to $1 /[\alpha(V)+\beta(V)]$, where $\alpha(V)$ and $\beta(V)$ are the rates leading to and from the inactivated state, respectively. To model the apparent saturation of the time constants at extreme voltages (more obvious for $\tau_{\text {recovery }}$ than for $\tau_{h}$ ), $\alpha(V)$ and $\beta(V)$ are made saturating functions of voltage (see Fig. 11 legend).

\section{DISCUSSION}

The primary motivation of this study was to test for a gating defect in the skeletal muscle L-type calcium channel caused by the hypokalemic periodic paralysis mutation R528H. A prerequisite of this goal was further characterization of the gating of the wild-type channel. We found two effects of the R528H mutation on the L-type Ca current in human myotubes. First, the current 
A.

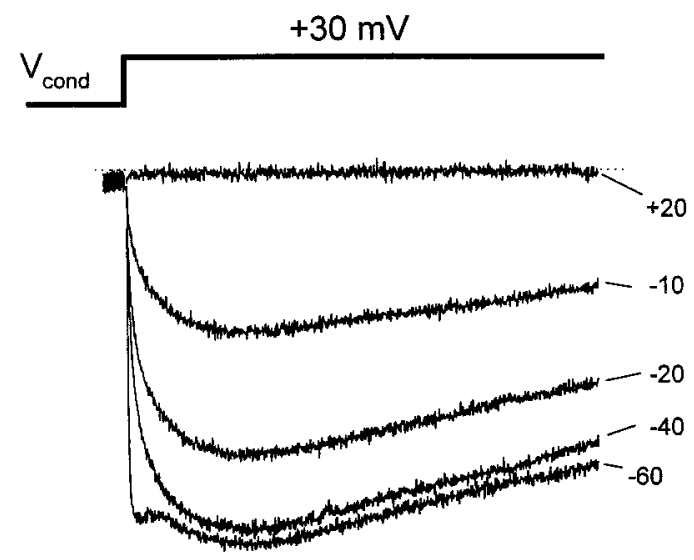

HypoPP

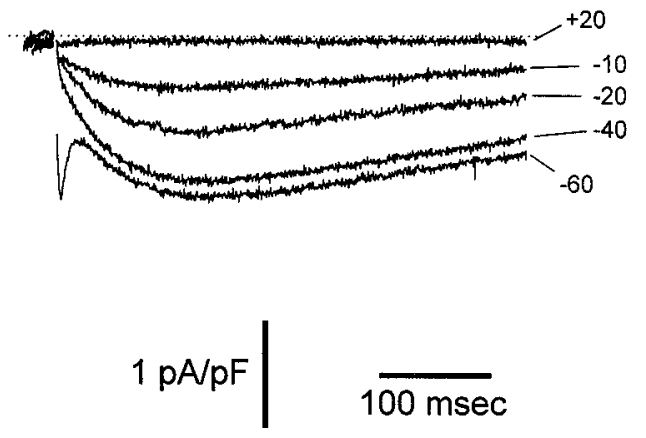

B.

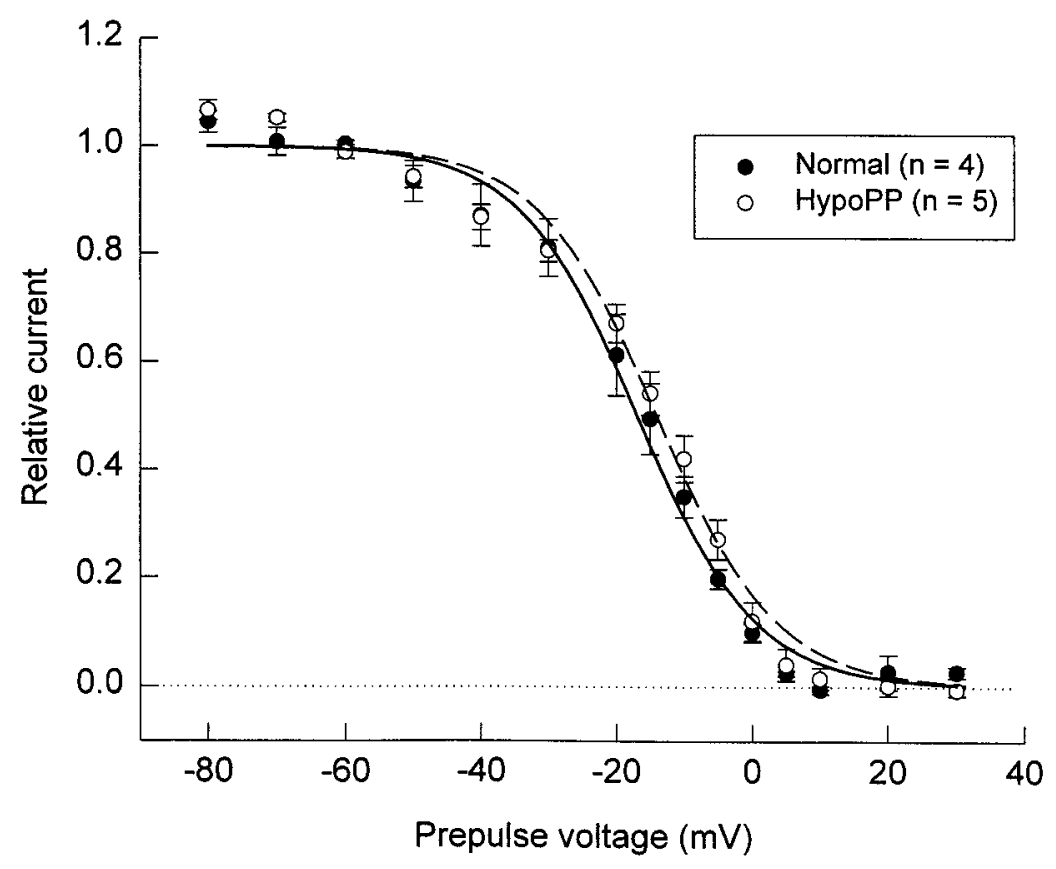

Figure 7. The voltage dependence of steady-state inactivation is identical in normal and HyopPP cells. $A$, Test currents were elicited by a 1 sec depolarization to $+30 \mathrm{mV}$ after a $60 \mathrm{sec}$ conditioning pulse $\left(V_{\text {cond }}\right)$ to a variety of conditioning potentials (indicated to the right of each trace). Leak-subtracted traces recorded from a normal cell and a HypoPP cell are presented in picoamperes per picofarad. In both normal and HypoPP cells, inactivation began near $-60 \mathrm{mV}$ and was complete at potentials above $+5 \mathrm{mV}$. The fast transient current observed after a conditioning pulse of -60 $\mathrm{mV}$ is the T-type Ca current. $B$, The fraction of current available after the $60 \mathrm{sec}$ conditioning pulse, measured $200 \mathrm{msec}$ after the onset of the test pulse, is plotted as a function of the conditioning voltage ( $n=4$ normal cells, from a single control patient, and 5 HypoPP cells). The solid and dashed lines are Boltzmann fits to the data from normal and HypoPP cells, respectively. Normal data: $V_{1 / 2}=-16.9 \pm 2.3 \mathrm{mV}$, and $k=8.7 \pm 1.4 \mathrm{mV}$. HypoPP data: $V_{1 / 2}=-14.0 \pm 1.3 \mathrm{mV}$, and $k=8.8 \pm 0.94 \mathrm{mV}$.

density was mildly reduced in heterozygous HypoPP myotubes. This observation agrees with the findings of Lerche et al. (1996) and Lapie et al. (1996), which showed reductions in current density of 38 and $75 \%$, respectively, when the R528H mutation was expressed in heterologous systems without contamination from the wild-type allele. On the other hand, it contrasts with results from native muscle cells or muscular dysgenesis myotubes expressing the rabbit $\alpha_{1 \mathrm{~S}}$ subunit (Sipos et al., 1995; Jurkat-Rott et al., 1998). Second, the rate of activation of the L-type Ca current was slowed in HypoPP myotubes, which has not been observed previously. The steepness and midpoint of the $G(V)$ curve and the deactivation rate were unaffected. 
A.
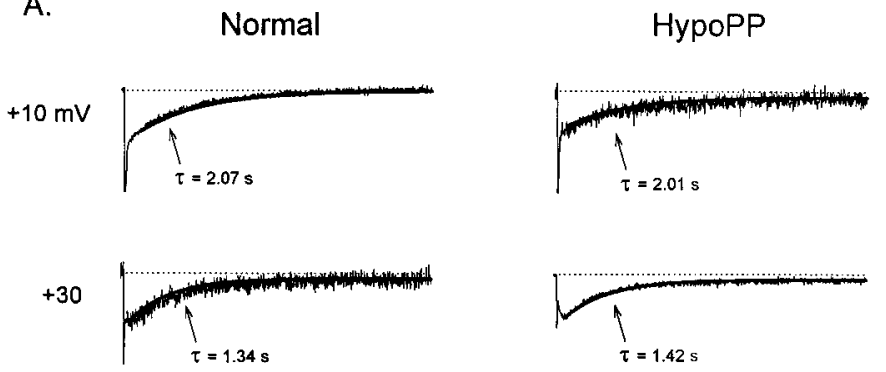

$+50$

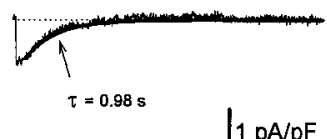

$1 \mathrm{pA} / \mathrm{pF} \quad 2 \mathrm{sec}$

B.

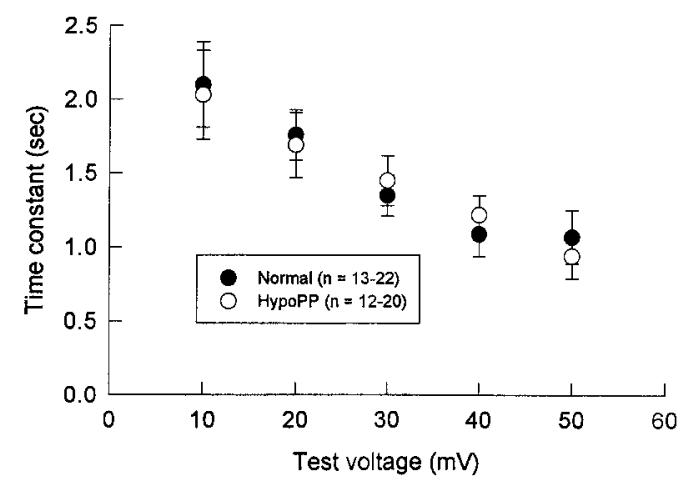

Figure 8. The rate of inactivation from the open state is the same in normal and HypoPP cells. $A$, Ca currents were evoked by $20 \mathrm{sec}$ depolarizations to various test potentials from a holding potential of $-100 \mathrm{mV}$. Currents, all from different cells, are leak subtracted and presented in picoamperes per picofarad. The solid lines are single exponential fits to the time course of inactivation. The transient inward currents at the start of the current traces are T-type Ca current. $B$, The time constant of inactivation $\tau_{h}$ was measured as described in $A$ and plotted as a function of test potential. Normal data are from cells derived from a single control subject. The rate of inactivation, which is similar in normal $(n=13-22)$ and HyopPP $(n=12-20)$ cells, becomes faster at more depolarized voltages.

\section{Activation of the skeletal muscle L-type calcium channel in human myotubes}

In both normal and HypoPP cells, activation of the L-type Ca current followed a Boltzmann distribution, with $V_{1 / 2}$ of approximately $+10 \mathrm{mV}$ and $k$ of $\sim 7 \mathrm{mV}$. This range and steepness of activation agrees fairly well with $I(V)$ curves measured with 10 $\mathrm{mM} \mathrm{Ca}{ }^{2+}$ as the charge carrier in other mammalian systems, including neonatal mouse myotubes (Beam and Knudson, 1988; Dirksen and Beam, 1995), mouse $m d g$ myotubes expressing the rabbit $\alpha_{1 \mathrm{~S}}$ subunit or a chimeric skeletal-cardiac L-type Ca channel (Garcia et al., 1997; Jurkat-Rott et al., 1998), human myotubes (Sipos et al., 1995, 1997; Jurkat-Rott et al., 1998), and adult human muscle fibers (Garcia et al., 1992). Under similar conditions, the range of activation in frog muscle is $30-40 \mathrm{mV}$ more negative (Cota et al., 1983; Sanchez and Stefani, 1983; Cota and Stefani, 1989).

A single exponential was adequate in most cases to describe the kinetics of activation, in agreement with previous studies in mammalian systems including muscle fibers from human (Garcia et al., 1992) and rat (Mejia-Alvarez et al., 1991; Delbono, 1992; Garcia et al., 1992), mouse myotubes (Tanabe et al., 1991; Dirksen and Beam, 1995), human myotubes (Sipos et al., 1997; JurkatRott et al., 1998), and bilayers containing the rabbit skeletal muscle L-type Ca channel (Ma et al., 1996). In frog fibers, activation of the L-type $\mathrm{Ca}$ channel is clearly sigmoidal and better fit by multiple-exponential schemes, such as the HodgkinHuxley $m^{3} * h$ model (Sanchez and Stefani, 1983) or more complicated multistate models (Francini et al., 1996). HypoPP is an autosomal dominant disorder, and therefore the HypoPP myotubes used in this and previous studies have all been heterozygous for R528H. Surprisingly, a single exponential described activation in the mutant cells as well as in the normal cells, suggesting that the time constant of activation of the mutant channels was never far enough from that of the normal channels to allow the resolution of two distinct components. The "pure" time constant of activation of the R528H channel is expected to be somewhat slower than the $\tau_{\mathrm{m}}$ values we measured in $\mathrm{R} 528 \mathrm{H}$ myotubes.

Although studies in adult frog and human fibers have shown that the rate of activation becomes faster with depolarization (Sanchez and Stefani, 1983; Feldmeyer et al., 1990; Garcia et al., 1992; Francini et al., 1996), we found that the rate of activation was essentially voltage independent in normal myotubes and became slower with depolarization for HypoPP myotubes. Sipos et al. (1997) and Jurkat-Rott et al. (1998) observed a similar effect in normal human myotubes; the single-exponential time constant of activation increased from $\sim 40-55 \mathrm{msec}$ at $+10 \mathrm{mV}$ to $60-75$ msec at +20 to $+50 \mathrm{mV}$, with very weak voltage dependence at $+20 \mathrm{mV}$ and above. In neonatal mouse myotubes, Dirksen and Beam (1995) also saw an upward trend of $\tau_{m}$ with voltage from $\sim 60 \mathrm{msec}$ at $0 \mathrm{mV}$ to $75 \mathrm{msec}$ at $+60 \mathrm{mV}$.

Caffrey (1994) fit the kinetics of activation with a sum of two exponential components $\left(\tau_{1}=2-20 \mathrm{msec}\right.$ and $\left.\tau_{2}=10-180 \mathrm{msec}\right)$ for L-type Ca currents recorded in mouse $\mathrm{BC} 3 \mathrm{H}$ cells. Although the two components, which Caffrey (1994) described as "modes" of activation, each became faster with voltage, the relative contribution of the slower mode was greater at more depolarized voltages, leading to a modest slowing of activation overall. A different type of voltage-dependent switch between activation modes has been described for L-type channels in rat heart cells, which shift from a low- $P_{o}$, slowly opening mode to a high- $P_{o}$, rapidly opening mode when the cell is depolarized $25-50 \mathrm{mV}$ above the half-maximal voltage of the $G(V)$ curve (Pietrobon and Hess, 1990). By analogy with these results, the apparent slowing of activation with depolarization seen by us and others in human and mouse myotubes might result from a modal shift in activation gating, with the two modes having time constants that are too similar to be resolved well in myotube recordings.

Another possible explanation for the apparent slowing is contamination by a high-threshold component of fast calcium current such as the third-type current described by Rivet et al. (1992), which would be expected to contribute most significantly to the time course at 0 to $+10 \mathrm{mV}$. However, this latter possibility seems unlikely given that (1) we were never able to isolate third-type current when we looked for it in normal and HypoPP myotubes and (2) third-type current, like T-type current, would be expected to be completely inactivated by a $2 \mathrm{sec}$ prepulse to $-30 \mathrm{mV}$ (Rivet et al., 1992).

The rate of activation of the L-type Ca current in $\mathrm{R} 528 \mathrm{H}$ myotubes was slower than in normal myotubes at all voltages, 
A.
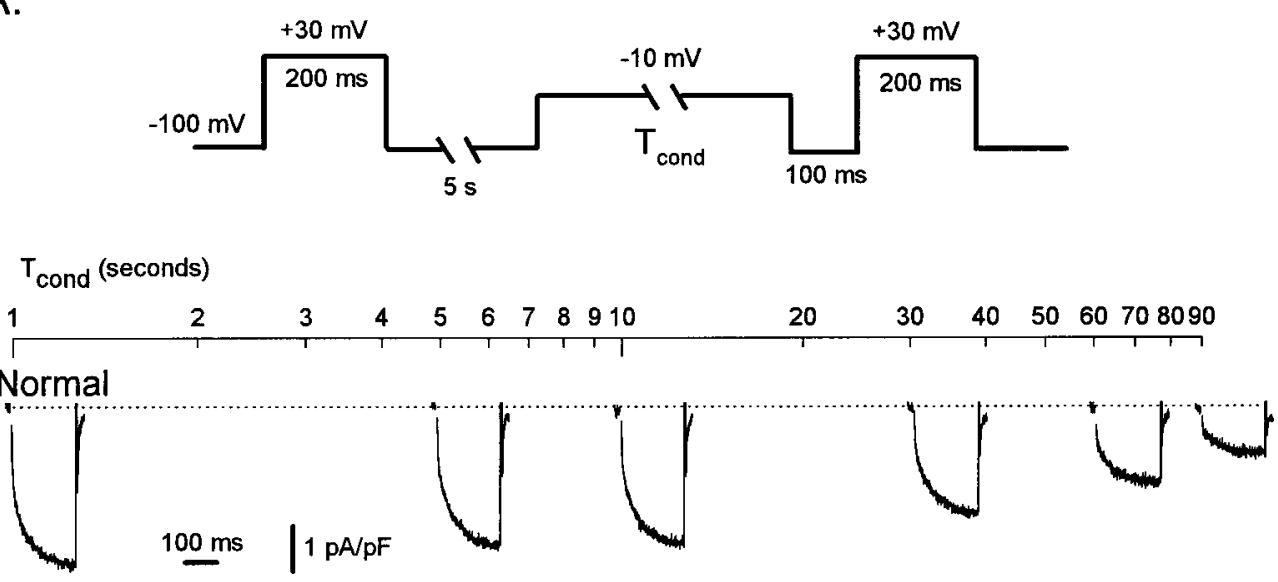

HypoPP

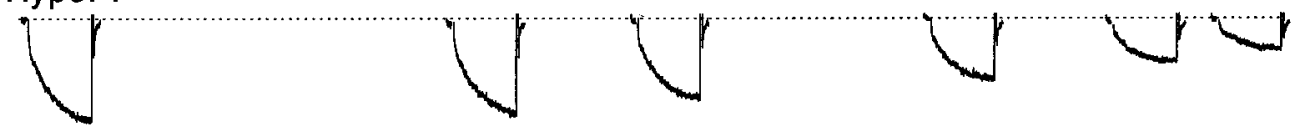

B.

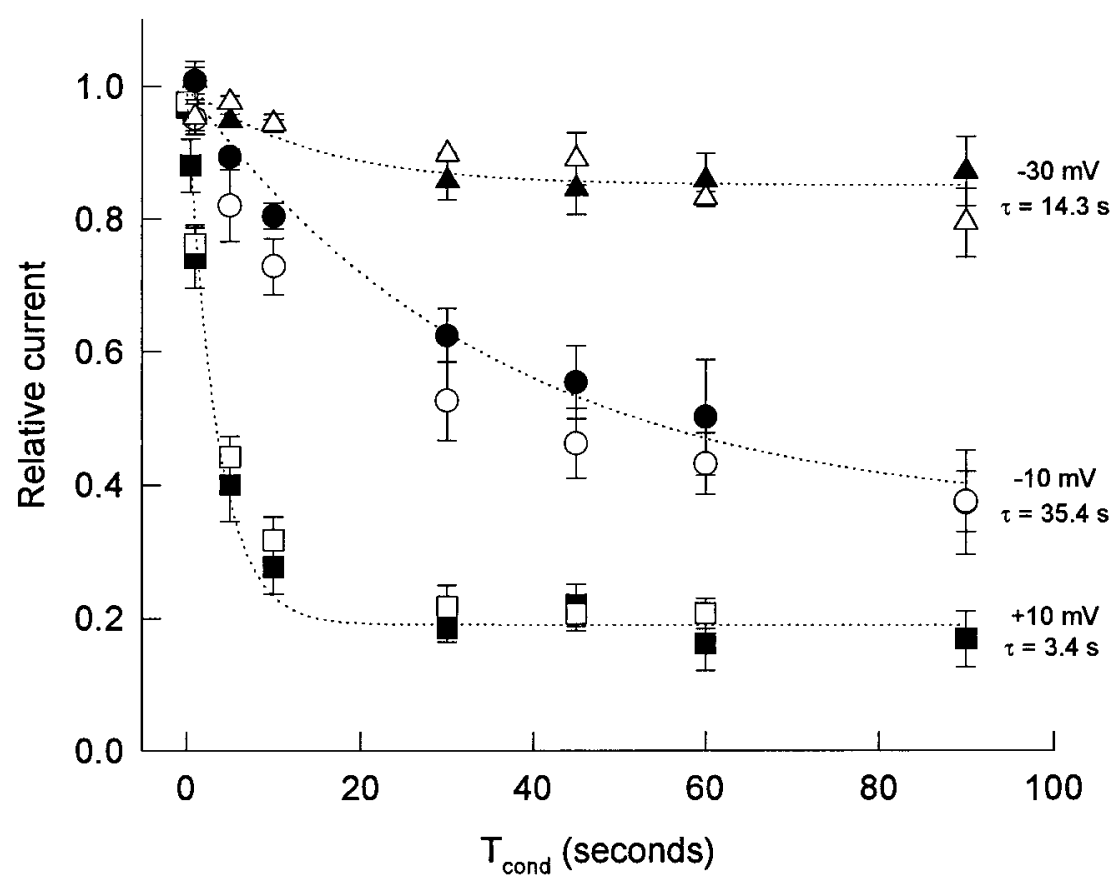

Figure 9. The rate of entry into the inactivated state at more hyperpolarized potentials is the same in normal and HypoPP myotubes. A, A three-pulse protocol (see inset) was used to measure the rate of entry. After a conditioning pulse of variable length (followed by a $100 \mathrm{msec}$ gap at $-100 \mathrm{mV}$ ), a test pulse to $+30 \mathrm{mV}$ measured the amount of L-type Ca current available, relative to a control current recorded before the conditioning pulse. The holding potential was $-100 \mathrm{mV}$, and the three-pulse sequence was repeated every $60-90 \mathrm{sec}$. $T_{\text {cond }}$, the length of the conditioning pulse, is shown on the horizontal logarithmic axis. The traces below, on a separate scale, show the test current recorded after conditioning pulses of the indicated length. Currents are leak subtracted and presented as picoamperes per picofarad. Capacitance transients are blanked at the start of each trace. B, The size of the test current, normalized by the control current, is plotted as a function of $T_{\text {cond }}$. Filled symbols are from normal cells (all from a single control patient), and hollow symbols are from HypoPP cells. Conditioning voltages are shown on the right $(-30 \mathrm{mV}, n=5$ normal cells and 3 HypoPP cells; $-10 \mathrm{mV}, n=3$ normal cells and 5 HypoPP cells; $+10 \mathrm{mV}, n=8$ normal cells and $8 \mathrm{HypoPP}$ cells). The dotted lines are single-exponential functions, fitted to the normal data, of the form: $\left(1-I_{\mathrm{o}}\right) * \exp \left(-t / \tau_{\mathrm{entry}}\right)+I_{\mathrm{o}}$, where $I_{\mathrm{o}}$ is the nonzero asymptote of the relaxation. The rate of entry into the inactivated state was similar in normal and HypoPP cells at all conditioning voltages tested. 
A.

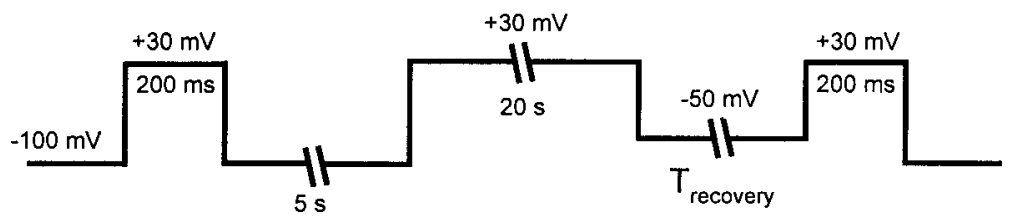

\section{$T_{\text {recovery }}$ (seconds)}

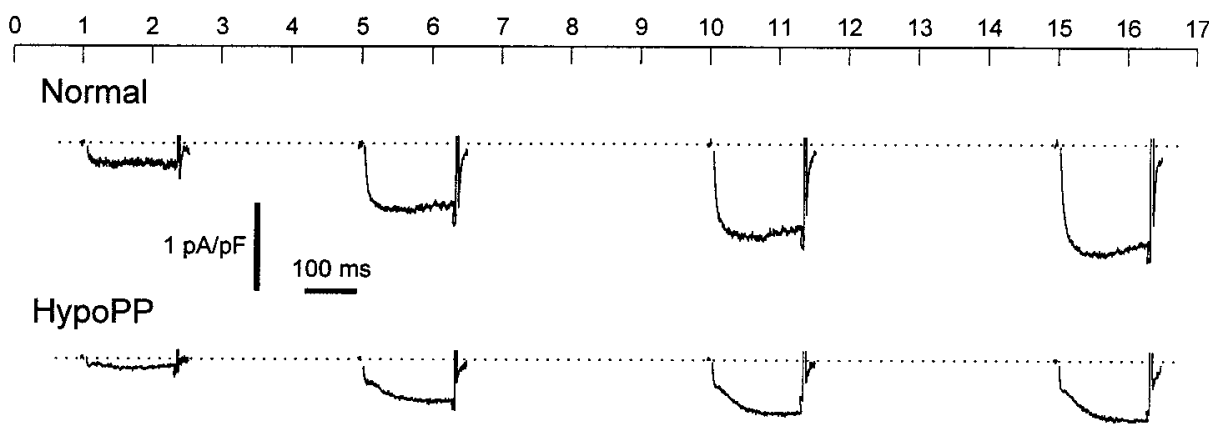

B.

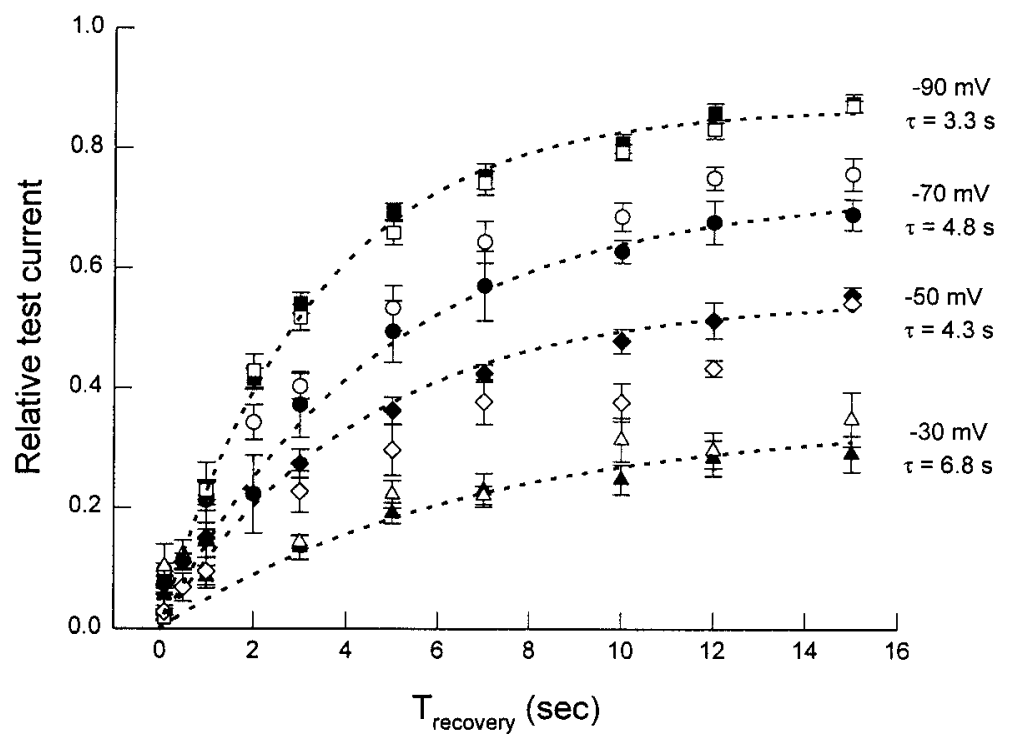

Figure 10. The rate of recovery from inactivation is the same in normal and HypoPP myotubes. $A$, A three-pulse protocol (see inset) was used to measure the rate of recovery from inactivation of the L-type Ca current. After a $30 \mathrm{sec}$ conditioning pulse to $+30 \mathrm{mV}$ (designed to inactivate all of the L-type current) and a variable-length gap for recovery, a test pulse to $+30 \mathrm{mV}$ was used to assay how much current had recovered, relative to a control current recorded before the conditioning pulse. The holding voltage was $-100 \mathrm{mV}$, and the pulse sequence was repeated every 60-90 sec. $T_{\text {recovery }}$, the length of the recovery gap, is shown on the horizontal linear axis. The traces below, on a separate scale, show currents recorded during the test pulse after the indicated recovery intervals. The currents are leak subtracted and presented as picoamperes per picofarad. The initial capacitive transient is blanked. $B$, For several recovery voltages (indicated on the right), the amount of current recovered relative to control is

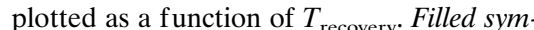
bols are from normal cells (derived from one control), and hollow symbols are from HypoPP cells $(-90 \mathrm{mV}, n=10$ normal and 9 HypoPP cells; $-70 \mathrm{mV}, n=5$ normal and 5 HypoPP cells; $-50 \mathrm{mV}, n=4$ normal and 3 HypoPP cells; $-30 \mathrm{mV}, n=$ 6 normal and 5 HypoPP cells). The dotted lines are single-exponential fits to the normal data of the form: $I_{\max } *[1-\exp (-t)$ $\left.\left.\tau_{\text {recovery }}\right)\right]$, where $I_{\max }$ is the asymptote of the relaxation. At all voltages tested, the L-type current in normal and HypoPP cells recovered from inactivation with a very similar time course. $I_{\max }$ is lower than the expected steady-state value at each voltage (see Fig. 7), suggesting that there was a very slow component of recovery from inactivation that was not seen on this time scale. which is consistent with the location of $\mathrm{R} 528 \mathrm{H}$, a partial neutralization of a charged arginine residue, at the outer end of the S4 voltage sensor of domain II. Substitutions for charged S4 residues in heterologously expressed potassium, sodium, and calcium channels also cause changes primarily in the voltage dependence or kinetics of activation (Stühmer et al., 1989; Liman et al., 1991; Papazian et al., 1991; Chen et al., 1996; Garcia et al., 1997). Neutralization of the analogous (outermost) arginine in the S4 segment of domain II of the skeletal muscle $\mathrm{Na}$ channel to cysteine causes a slight rightward shift and modest reduction in slope of the $G(V)$ curve, and modification of the mutant cysteine with the cationic sulfhydryl reagent MTSET has further effects on activation, both biasing the channel toward the open state and dramatically slowing displacement of domain II S4 back and forth across the membrane (Mitrovic et al., 1998). Replacement of the outermost arginine of domain IV S4 with histidine in the skeletal muscle $\mathrm{Na}$ channel has negligible effects on activation, instead disrupting the coupling of activation to inactivation (Chahine et al., 1994). Histidine has a $\mathrm{p}_{\mathrm{Ka}}$ of 6-8 in proteins (Fersht, 1985; Lu and MacKinnon, 1995) and affects gating in a pH-dependent manner when engineered into the S4 region of the Shaker $\mathrm{K}^{+}$ channel (Starace et al., 1997) or the S4 region of domain IV of the sodium channel (Chahine et al., 1994). However, varying the extracellular $\mathrm{pH}$ from 6 to 9 did not alter activation rates in R528H myotubes (data not shown).

Surprisingly, the R528H mutation did not affect the position or steepness of the $G(V)$ curve, suggesting that the apparent gating charge of the channel, as well as the equilibrium energy difference between states along the activation pathway, was unaffected. The effect of $\mathrm{R} 528 \mathrm{H}$ on the activation rate, however, implies that this 
Figure 11. The voltage dependence of entry into and recovery from inactivation is the same in normal and HypoPP myotubes. Time constants from the singleexponential fits to the time courses of entry (Figs. 8, 9) and recovery (Fig. 10) are combined on a semilogarithmic plot. Filled symbols are for normal cells; open symbols are for HypoPP cells. Inverted triangles are recovery time constants (Fig. 10), circles are twopulse entry time constants (Fig. 9), and squares are time constants of inactivation from the open state (Fig. 8). The solid line is a fit of a two-state model of inactivation to the data from normal cells. In this model, the time constant of inactivation is $1 /(\alpha+\beta)$, where $\alpha$ and $\beta$ are the rate constants leading into and out of the inactivated state, respectively. The rate constants are saturating functions of membrane voltage: $\alpha(V)=\alpha_{\max } /\left(1+\exp \left[-\left(V-V_{1 / 2 \alpha}\right) / k_{\alpha}\right]\right)$, and $\beta(V)=\beta_{\max } /\left(1+\exp \left[\left(V-V_{1 / 2 \beta}\right) / k_{\beta}\right]\right)$, where $\alpha_{\max }$ $=0.88 \mathrm{sec}^{-1}, \beta_{\max }=0.33 \mathrm{sec}^{-1}, V_{1 / 2 \alpha}=17.4 \mathrm{mV}, k_{\alpha}$ $=5.8 \mathrm{mV}, V_{1 / 2 \beta}=-53.6 \mathrm{mV}$, and $k_{\beta}=16.4$.

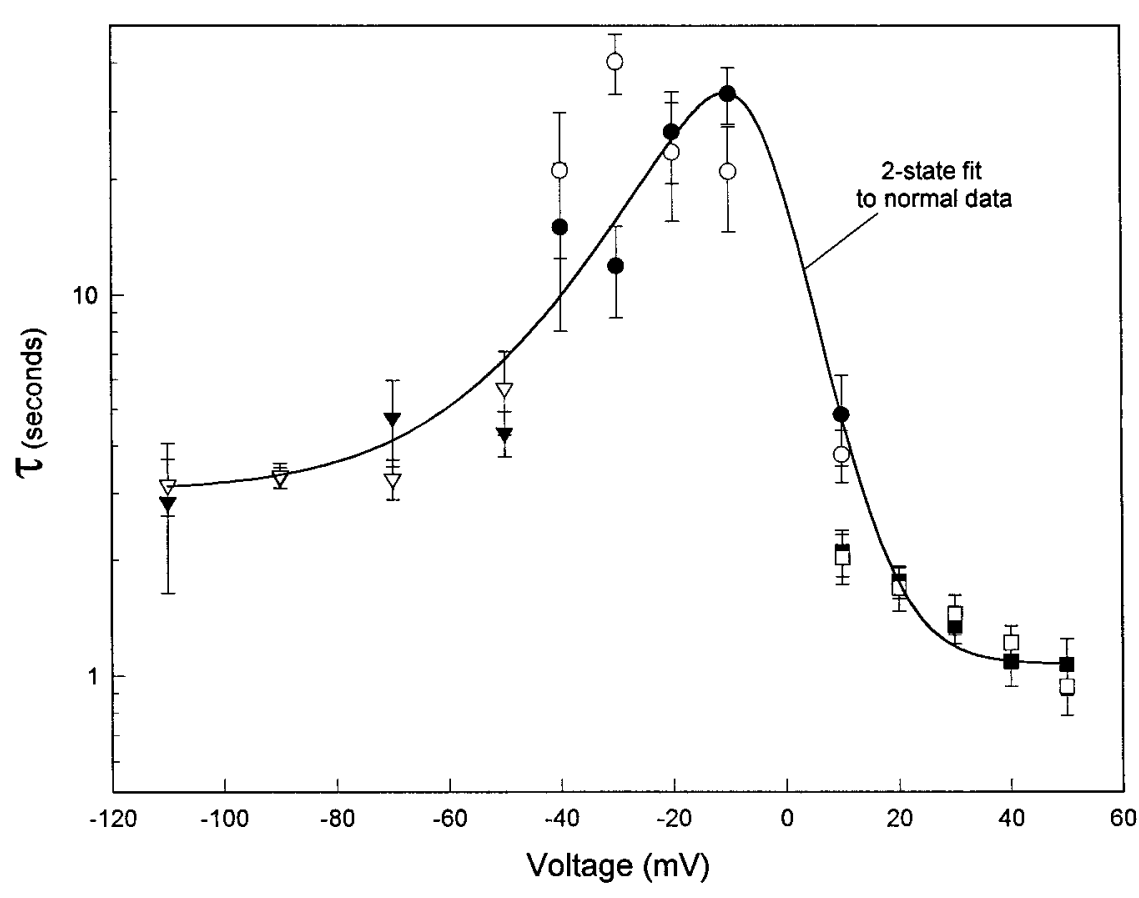

mutation affected a transition state along the activation pathway, thereby either slowing the rate-limiting step in activation or slowing some other step enough to make it rate-limiting. Because deactivation was unaffected by the mutation, it is unlikely that $\mathrm{R} 528 \mathrm{H}$ affected the final step in a sequential gating scheme. However, if the channel is governed by a cyclic gating scheme, as proposed by several others (Feldmeyer et al., 1990; Ma et al., 1996; Sipos et al., 1997), the mutation could have affected the final step in the process of activation without affecting the rate of deactivation. Our results, which implicate the S4 segment of domain II in helping to set the activation kinetics of the skeletal muscle L-type Ca channel, contrast with chimeric studies and scanning mutagenesis studies in the mouse $m d g$ myotube system that identify parts in or near the S4 regions of domains I and III, as opposed to domains II and IV, as the crucial determinants of the activation rate of the channel (Tanabe et al., 1991; Nakai et al., 1994; Garcia et al., 1997). It is possible that the activation rate is sensitive to selective alterations in the outermost part of domain II S4, a region that was not specifically targeted in these previous studies.

\section{Inactivation}

Although an early paper comparing normal and R528H human myotubes found that the mutation caused a striking $40 \mathrm{mV}$ hyperpolarizing shift in the voltage dependence of steady-state inactivation (Sipos et al., 1995), a recent report from the same group failed to confirm this finding in myotubes from additional HypoPP patients and revealed only a modest $(8 \mathrm{mV})$ leftward shift in the steady-state inactivation curve in $\mathrm{R} 528 \mathrm{H}$ myotubes (Jurkat-Rott et al., 1998). Using $60 \mathrm{sec}$ conditioning pulses, we found no difference in the voltage dependence of steady-state inactivation between normal and HypoPP myotubes. The $V_{1 / 2}$ in normal and HypoPP cells was approximately $-17 \mathrm{mV}$, which is more hyperpolarized than the value measured by Sipos et al. (1995) and Jurkat-Rott et al. (1998) in normal human myotubes $\left(V_{1 / 2}=-1\right.$ to $\left.-5 \mathrm{mV}\right)$. This difference is most likely explained by the shorter conditioning pulse lengths of 15 and $20 \mathrm{sec}$, respectively, used in the previous studies, which did not allow inactiva- tion to proceed all the way to steady state at hyperpolarized potentials (see below). Our $V_{1 / 2}$ of $-17 \mathrm{mV}$ was significantly more depolarized than the values measured in frog fibers $\left[V_{1 / 2}=-30\right.$ to $-40 \mathrm{mV}$ in $10 \mathrm{mM} \mathrm{Ca}^{2+}$ (Sanchez and Stefani, 1983; Cota and Stefani, 1989)], cut rat fibers $\left[V_{1 / 2}=-48 \mathrm{mV}\right.$ in $2 \mathrm{mM} \mathrm{Ca}^{2+}$ (Mejia-Alvarez et al., 1991)], or lipid bilayers containing the rabbit channel $\left[V_{1 / 2}=-32 \mathrm{mV}\right.$ in $100 \mathrm{~mm} \mathrm{Ba}^{2+}$ (Mejia-Alvarez et al., 1991)]. The steepness factor was 8.7, in good agreement with values previously found in human myotubes $[k=8-9 \mathrm{mV}$ (Jurkat-Rott et al., 1998)].

We also measured the rates of entry into and exit from inactivation at a range of voltages and found no significant differences between normal and $\mathrm{R} 528 \mathrm{H}$ cells. The time course of entry from the open state at depolarized voltages or from closed states at hyperpolarized voltages was monoexponential and occurred on a timescale of seconds, as seen by many investigators (Sanchez and Stefani, 1983; Mejia-Alvarez et al., 1991; Francini et al., 1992; Delbono and Stefani, 1993; Caffrey, 1994; Jurkat-Rott et al., 1998). Where entry was slowest, at -10 to $-20 \mathrm{mV}$, inactivation was complete in 60-90 sec, underscoring the importance of using long ( $\geq 60 \mathrm{sec}$ ) conditioning pulses to measure steady-state inactivation. Recovery from inactivation had an initial singleexponential phase (over the first $15 \mathrm{sec}$ ) that was incomplete, judging from the voltage dependence of steady-state inactivation. This phase became faster and more complete with hyperpolarization, reaching a point of saturation at -90 to $-100 \mathrm{mV}$, but never accounted for $>85 \%$ of the expected recovery, implying that recovery had a very slow phase that was completed during the 60-90 sec interval between pulse sequences.

\section{Implications for HypoPP}

Our study demonstrates that muscle cells cultured from a HypoPP patient carrying the $\mathrm{R} 528 \mathrm{H}$ mutation express an abnormal L-type Ca current. In addition to mildly reducing the density of L-type Ca current, the mutation causes a selective slowing of the activation rate of the channel without affecting other gating properties of the ionic current, including inactivation.

Neither of these abnormalities immediately suggests a patho- 
physiological mechanism for HypoPP. Because the L-type calcium channel plays a dual role in muscle as a calcium channel and as a voltage sensor for excitation-contraction (E-C) coupling (Rios and Brum, 1987; Tanabe et al., 1988), it is possible that activation of the calcium release process is slowed as well as activation of the L-type $\mathrm{Ca}$ current. This could give rise to impaired E-C coupling and, if the impairment is severe enough, paralysis. In principle, this possibility can be tested by recording gating currents and by monitoring calcium transients with calcium-sensitive dyes. Although native L-type Ca channel gating currents have been successfully measured in mouse myotubes (Beam and Knudson, 1988), gating current measurements have not been attempted in human myotubes, where the L-type $\mathrm{Ca}$ current density is several-fold lower. Calcium transients, on the other hand, have been shown to be robust in human myotubes (Brown et al., 1995) and were recently recorded in HypoPP myotubes carrying the R528H mutation (Jurkat-Rott et al., 1998). In the latter study, calcium release was determined to be identical in normal and $\mathrm{R} 528 \mathrm{H}$ myotubes.

Another possible pathophysiological mechanism is that the disruption of L-type $\mathrm{Ca}$ channel gating promotes paralysis by impairing electrical excitability. In vitro studies of biopsied fibers showed that the paralysis observed clinically arises from aberrant depolarization of the resting potential of the muscle cell (Rüdel et al., 1984); the cause of this depolarization remains unknown. Although the L-type Ca channel has long been thought to be an effector molecule that senses the voltage across the t-tubular membrane to trigger calcium influx and release, there is no evidence that the channel makes a significant contribution to the muscle resting potential. Moreover, our data give no indication that the mutant channel is open abnormally at potentials near the firing threshold. Thus, a persistent inward current through mutant L-type Ca channels is unlikely to be the cause for the anomalous depolarization. However, it is possible that calcium either conducted through the L-type Ca channel or released from the sarcoplasmic reticulum acts as a messenger that feeds back on the membrane potential, perhaps by opening local calciumactivated potassium channels (Jacquemond and Allard, 1998). In mature muscle, large-conductance $\mathrm{K}(\mathrm{Ca})$ channels are found in the t-tubules (Latorre et al., 1989), where the L-type Ca channel is known to reside, and physiologically important colocalization of $\mathrm{K}(\mathrm{Ca})$ and $\mathrm{Ca}$ channels has been demonstrated in bullfrog saccular hair cells (Roberts et al., 1990) and snail neurons (Gola and Crest, 1993). In such a feedback scheme, the L-type Ca channel is indirectly related to the membrane potential, and its normal function of supplying calcium in a timely manner in response to depolarization serves a protective purpose. A reduction in the L-type $\mathrm{Ca}$ current density or a delay in the activation of the channel during activity might disrupt the ability of $\mathrm{K}(\mathrm{Ca})$ channels to rescue the muscle cell after a series of action potentials, leading to depolarization and a failure of conduction.

As suggested by Jurkat-Rott et al. (1998), it is also possible that the R528H mutation has no significant effect on E-C coupling or on the electrical behavior of adult muscle cells but rather alters expression of other muscle proteins during development, giving rise to an abnormal electrical environment in the mature muscle fiber that allows potassium-sensitive paralysis. Jurkat-Rott et al. (1998) found modest parallel shifts in the voltage dependence of the L-type, T-type, and third-type calcium currents in $\mathrm{R} 528 \mathrm{H}$ myotubes compared with normal myotubes, suggesting that some common regulatory mechanism was different in the mutant cells. Other preliminary work has revealed a reduction in $\mathrm{K}$ current density near the resting potential in biopsied mature HypoPP fibers compared with normal fibers (Ruff, 1998) that could render these fibers more susceptible to abnormal depolarization. A resolution of the basis for this diversity of altered behavior in HypoPP fibers and of the pathophysiological basis of fiber weakness will likely require the development of an in vivo model, such as a targeted "knock-in" mutation in mice.

\section{REFERENCES}

Adams BA, Tanabe T, Beam KG (1996) $\mathrm{Ca}^{2+}$ current activation rate correlates with $\alpha_{1}$ subunit density. Biophys J 71:156-162.

Beam KG, Knudson GM (1988) Calcium currents in embryonic and neonatal mammalian skeletal muscle. J Gen Physiol 91:781-798.

Brown SC, Beurg M, Grouselle M, Koenig J, Krueger S, Lucy JA, Georgescauld D (1995) Spatial and temporal distribution of $\left[\mathrm{Ca}^{2+}\right]_{\mathrm{i}}$ in normal human myotubes: a fura-2 imaging study. Eur J Cell Biol 66:382-388.

Caffrey JM (1994) Kinetic properties of skeletal-muscle-like highthreshold calcium currents in a non-fusing muscle cell line. Pflügers Arch 427:277-288.

Chahine M, George AL, Zhou M, Ji S, Sun W, Barchi RL, Horn R (1994) Sodium channel mutations in paramyotonia congenita uncouple inactivation from activation. Neuron 12:281-294.

Chen L-Q, Santarelli V, Horn R, Kallen RG (1996) A unique role for the S4 segment of domain 4 in the inactivation of sodium channels. J Gen Physiol 108:549-556.

Cota G, Stefani E (1989) Voltage-dependent inactivation of slow calcium channels in intact twitch muscle fibers of the frog. J Gen Physiol 94:937-951.

Cota G, Nicola Siri L, Stefani E (1983) Calcium-channel gating in frog skeletal muscle membrane: effect of temperature. J Gen Physiol 338:395-412.

Delbono O (1992) Calcium current activation and charge movement in denervated mammalian skeletal muscle fibres. J Physiol (Lond) 451:187-203.

Delbono O, Stefani E (1993) Calcium current inactivation in denervated rat skeletal muscle fibres. J Physiol (Lond) 460:173-183.

Dirksen RT, Beam KG (1995) Single calcium channel behavior in native skeletal muscle. J Gen Physiol 105:227-247.

Feldmeyer D, Melzer W, Pohl B, Zollner P (1990) Fast gating kinetics of the slow $\mathrm{Ca}^{2+}$ current in cut skeletal muscle fibres of the frog. J Physiol (Lond) 425:347-367.

Fersht A (1985) Enzyme structure and mechanism. New York: Freeman.

Fontaine B, Vale-Santos J, Jurkat-Rott K, Reboul J, Plassart E, Rime CS, Elbaz A, Heine R, Guimaraes J, Weissenbach J (1994) Mapping of the hypokalaemic periodic paralysis (HypoPP) locus to chromosome 1q31-32 in three European families. Nat Genet 6:267-272.

Fouad G, Dalakas M, Servidei S, Mendell JR, Van den Bergh P, Angelini C, Alderson K, Griggs RC, Tawil R, Gregg R, Hogan K, Powers PA, Weinberg N, Malonee W, Ptacek LJ (1997) Genotype-phenotype correlations of DHP receptor $\alpha_{1}$-subunit gene mutations causing hypokalemic periodic paralysis. Neuromuscular Disorders 7:33-38.

Francini F, Pizza L, Traina G (1992) Inactivation of the slow calcium current in twitch skeletal muscle fibres of the frog. J Physiol (Lond) 448:633-653.

Francini F, Bencini C, Squecco R (1996) Activation of L-type calcium channel in twitch skeletal muscle fibres of the frog. J Physiol (Lond) 494:121-140.

Garcia J, McKinley K, Appel SH, Stefani E (1992) $\mathrm{Ca}^{2+}$ current and charge movement in adult single human skeletal muscle fibres. J Physiol (Lond) 454:183-196.

Garcia J, Nakai J, Imoto K, Beam KG (1997) Role of S4 segments and the leucine heptad motif in the activation of an L-type calcium channel. Biophys J 72:2515-2523.

Gola M, Crest M (1993) Colocalization of active KCa channels and $\mathrm{Ca}^{2+}$ channels within $\mathrm{Ca}^{2+}$ domains in Helix neurons. Neuron 10:689-699.

Jacquemond V, Allard B (1998) Activation of $\mathrm{Ca}^{2+}$-activated $\mathrm{K}^{+}$channels by an increase in intracellular $\mathrm{Ca}^{2+}$ induced by depolarization of mouse skeletal muscle fibres. J Physiol (Lond) 509:93-102.

Jurkat-Rott K, Lehmann-Horn F, Elbaz A, Heine R, Gregg RG, Hogan K, Powers PA, Lapie P, Vale-Santos JE, Weissenbach J, Fontaine B (1994) A calcium channel mutation causing hypokalemic periodic paralysis. Hum Mol Genet 3:1415-1419. 
Jurkat-Rott K, Uetz U, Pika-Hartlaub U, Powell J, Fontaine B, Melzer W, Lehmann-Horn F (1998) Calcium currents and transients of native and heterologously expressed mutant skeletal muscle DHP receptor $\alpha_{1}$ subunits (R528H). FEBS Lett 423:198-204.

Lapie P, Goudet C, Nargeot J, Fontaine B, Lory P (1996) Electrophysiological properties of the hypokalaemic periodic paralysis mutation (R528H) of the skeletal muscle $\alpha_{1 \mathrm{~S}}$ subunit as expressed in mouse $\mathrm{L}$ cells. FEBS Lett 382:244-248.

Latorre R, Oberhauser A, Labarca P, Alvarez O (1989) Varieties of calcium-activated potassium channels. Annu Rev Physiol 51:385-399.

Lehmann-Horn F, Engel AG, Ricker K, Rüdel R (1994) The periodic paralyses and paramyotonia congenita. In: Myology (Engel AG, Franzini-Armstrong C, eds) pp 1303-1334. New York: McGraw-Hill.

Lerche H, Klugbauer N, Lehmann-Horn F, Hofmann F, Melzer W (1996) Expression and functional characterization of the cardiac L-type calcium channel carrying a skeletal muscle DHP-receptor mutation causing hypokalaemic periodic paralysis. Pflügers Arch 431:461-463.

Liman ER, Hess P, Weaver F, Koren G (1991) Voltage-sensing residues in the $\mathrm{S} 4$ region of a mammalian $\mathrm{K}^{+}$channel. Nature 353:752-756.

Lu Z, MacKinnon R (1995) Probing a potassium channel pore with an engineered protonatable site. Biochemistry 34:13133-13138.

Ma J, Mundina-Weilenmann C, Hosey MM, Rios E (1991) Dihydropyridine-sensitive skeletal muscle $\mathrm{Ca}$ channels in polarized planar bilayers. 1. Kinetics and voltage dependence of gating. Biophys J 60:890-901.

Ma J, Gonzalez A, Chen R (1996) Fast activation of dihydropyridinesensitive calcium channels of skeletal muscle: multiple pathways of channel gating. J Gen Physiol 108:221-232.

Mejia-Alvarez R, Fill M, Stefani E (1991) Voltage-dependent inactivation of t-tubular skeletal calcium channels in planar lipid bilayers. J Gen Physiol 97:393-412.

Mitrovic N, George AL, Horn R (1998) Independent versus coupled inactivation in sodium channels: role of the domain 2 S4 segment. J Gen Physiol 111:451-462.

Nakai J, Adams BA, Imoto K, Beam KG (1994) Critical roles of the S3 segment and S3-S4 linker of repeat I in activation of L-type calcium channels. Proc Natl Acad Sci USA 91:1014-1018.

Papazian DM, Timpe LC, Jan YN, Jan LY (1991) Alteration of voltagedependence of Shaker potassium channel by mutations in the S4 sequence. Nature 349:305-310.

Pietrobon D, Hess P (1990) Novel mechanism of voltage-dependent gating in L-type calcium channels. Nature 346:651-655.

Ptacek LJ, Tawil R, Griggs RC, Engel AG, Layzer RB, Kwiecinski H,
McManis PG, Santiago L, Moore M, Fouad G (1994) Dihydropyridine receptor mutations cause hypokalemic periodic paralysis. Cell 77:863-868

Rios E, Brum G (1987) Involvement of dihydropyridine receptors in excitation-contraction coupling in skeletal muscle. Nature 325:717-720.

Rivet M, Cognard C, Imbert N, Rideau Y, Duport G, Raymond G (1992) A third type of calcium current in cultured human skeletal muscle cells. Neurosci Lett 138:97-102.

Roberts WM, Jacobs RA, Hudspeth AJ (1990) Colocalization of ion channels involved in frequency selectivity and synaptic transmission at presynaptic active zones of hair cells. J Neurosci 10:3664-3684.

Rüdel R, Lehmann-Horn F, Ricker K, Kuther G (1984) Hypokalemic periodic paralysis: in vitro investigation of muscle fiber membrane parameters. Muscle Nerve 7:110-120.

Ruff RL (1991) Calcium-tension relationships of muscle fibers from patients with periodic paralysis. Muscle Nerve 14:838-844.

Ruff RL (1998) Insulin potentiates depolarization-induced paralysis in human hypokalemic periodic paralysis by reducing inward rectifier $\mathrm{K}$ channel conductance. Biophys J 74:A360.

Sanchez JA, Stefani E (1983) Kinetic properties of calcium channels in twitch muscle fibres of the frog. J Physiol (Lond) 337:1-17.

Sipos I, Jurkatt-Rott K, Harasztosi C, Fontaine B, Kovacs L, Melzer W, Lehmann-Horn F (1995) Skeletal muscle DHP receptor mutations alter calcium currents in human hypokalaemic periodic paralysis myotubes. J Physiol (Lond) 483:299-306.

Sipos I, Harasztosi C, Melzer W (1997) L-type calcium current activation in cultured human myotubes. J Muscle Res Cell Motil 18:353-367.

Starace DM, Stefani E, Bezanilla F (1997) Voltage-dependent proton transport by the voltage sensor of the Shaker $\mathrm{K}^{+}$channel. Neuron 19:1319-1327.

Stühmer W, Conti F, Suzuki H, Wang X, Noda M, Yahagi N, Kubo H, Numa S (1989) Structural parts involved in activation and inactivation of the sodium channel. Nature 339:597-603.

Tanabe T, Beam KG, Powell JA, Numa S (1988) Restoration of excitation-contraction coupling and slow calcium current in dysgenic muscle by dihydropyridine receptor complementary DNA. Nature 336:134-139.

Tanabe T, Adams BA, Numa S, Beam KG (1991) Repeat I of the dihydropyridine receptor is critical in determining calcium channel activation kinetics. Nature 352:800-803.

Welkowitz J, Ewen RB, Cohen J (1976) One-way analysis of variance. In: Introductory statistics for the behavioral sciences, pp 206-228. New York: Academic. 